\title{
Observational and Synoptic Analyses of the Winter Precipitation Regime Change over Utah
}

\author{
ROBERT R. GILliES AND SHIH-YU WANG \\ Utah Climate Center, and Department of Plants, Soils, and Climate, \\ Utah State University, Logan, Utah \\ MARTY R. BOOTH \\ Utah Climate Center, Utah State University, Logan, Utah
}

(Manuscript received 8 February 2011, in final form 10 January 2012)

\begin{abstract}
Previous studies have indicated a widespread decline in snowpack over Utah accompanied by a decline in the snow-precipitation ratio while anecdotal evidence claims have been put forward that measured changes in Utah's snowpack are spurious and do not reflect actual change. Using two distinct lines of investigation, this paper further analyzes the winter precipitation regime in the state of Utah. First, by means of observationbased, gridded daily temperature, precipitation, and remotely sensed data, as well as utilizing a climatological rain-snow threshold (RST) temperature method, the precipitation regime of Utah was scrutinized. Second, a comprehensive synoptic analysis was conducted as an alternate means that is independent from surface observations. It was found that the proportion of winter (January-March) precipitation falling as snow has decreased by $9 \%$ during the last half century, a combined result from a significant increase in rainfall and a minor decrease in snowfall. Meanwhile, observed snow depth across Utah has decreased and is accompanied by consistent decreases in snow cover and surface albedo. Weather systems with the potential to produce precipitation in Utah have decreased in number with those producing snowfall decreasing at a considerably greater rate. Further circulation analysis showed that an anomalous anticyclone has developed over western North America, which acts to reduce the frequency of cyclone waves impacting Utah. Combined with the increased precipitation, this feature suggests that the average precipitation per event has intensified with more of it falling as rain than as snow. Trends in the hydroclimate such as these have implications for present and future regional water policy in the state of Utah.
\end{abstract}

\section{Introduction}

The development of a heavy winter mountain snowpack in the U.S. Intermountain West is crucial for sustaining the region's water resources. Specifically, the retention of water in the snowpack and its timely release is an overriding factor of the hydrological cycle for the region. A wealth of observational evidence of the hydroclimate in the Intermountain West indicates a pronounced declining trend in the snowpack coupled to changes in meltoff and runoff-both of which are occurring earlier in the season (Lettenmaier and Gan 1990; McCabe and Wolock 1999; Cayan et al. 2001; Dettinger et al. 2004;

Corresponding author address: Dr. Robert R. Gillies, Utah Climate Center, Utah State University, 4825 Old Main Hill, Logan, UT 84322-4825.

E-mail: robert.gillies@usu.edu
Stewart et al. 2004, 2005; Mote 2006); these phenomena have been attributed to widespread warming occurring across the western United States (Barnett et al. 2005; Hamlet et al. 2005; Regonda et al. 2005; Pierce et al. 2008). Moreover, these conditions are exacerbated by a shift in the fraction of precipitation that falls as rain rather than snow (e.g., Knowles et al. 2006) as this reduces snowpack (Karl et al. 1993; Leung et al. 2004).

Many of the studies that have addressed such climate change conditions have concentrated on specific mountain ranges such as the Sierra Nevada (Pupacko 1993; Howat and Tulaczyk 2005), the Cascade Range (e.g., Leung and Ghan 1999), and the Colorado Rockies (Christensen et al. 2004). Comparatively, change in the winter precipitation regime over the state of Utah, which encompasses the Wasatch Range, has received less attention. Precipitation in and around Utah experiences a pronounced semiannual variability characterized by 
large spring amounts in the north and summer monsoon rain in the south, a feature that is distinct from the winter-dominant precipitation regime of the CascadeSierra Range and the Pacific Northwest (Wang et al. 2009b). Also of interest is the fact that, despite the documented decline in springtime snow water equivalent (SWE) during the past decades (e.g., Mote 2006), winter precipitation in Utah has increased (Regonda et al. 2005) while the snowfall water equivalent $S$ reveals a wide range of trends (Knowles et al. 2006; their Fig. 3b). Since spring SWE is strongly related to winter precipitation, these two trends seem to be diametrically opposite (although a larger fraction of precipitation falling as rain could also cause an increase in precipitation and a decrease in snowpack).

The majority of the aforementioned snow-related studies used snow-course surveys and snow telemetry (SNOTEL) stations, which are mostly distributed along mountain ranges over high elevations. Of relevance here is a recent presentation by Julander (2010), derived from an earlier government document (Julander and Bricco 2006) and a collection of anecdotal evidence, in which it was claimed that measured changes in Utah's snowpack from snow courses and SNOTEL stations are spurious - the result of errors attributable to poor instrument siting such as land-use changes at instrument locations, rather than one that portrays an accurate reflection of actual change in climate in the region. These public claims, while not peer-reviewed (see, e.g., http:// pielkeclimatesci.wordpress.com/2011/06/24/uncertaintyin-utah-hydrologic-data-part-2-streamflow-data-set-byrandall-p-julander/), are contrary to published evidence that suggest otherwise (e.g., Mote 2006; Pierce et al. 2008) and have created confusion in the area of regional water policy. It is therefore timely and necessary to explore further the uncertainty and dynamics associated with the observed precipitation regime change.

Thus, in our examination of change and trends in the snow and precipitation regime for the state of Utah, we performed a concomitant series of analyses encompassing variables other than the snow courses and the SNOTEL stations. We utilized a number of observed and assimilated datasets and an applied climatological approach - that is, one that computes probability density functions of temperatures that are used to separate rainfall from snowfall in the precipitation measurements; these are introduced and evaluated in section 2. In section 3 we then chart trends and variability of different meteorological variables; the subsequent analysis of which describe the winter precipitation regime change. Finally, in section 4, a coherent set of consistent conclusions arising from these analyses are brought together and reviewed.

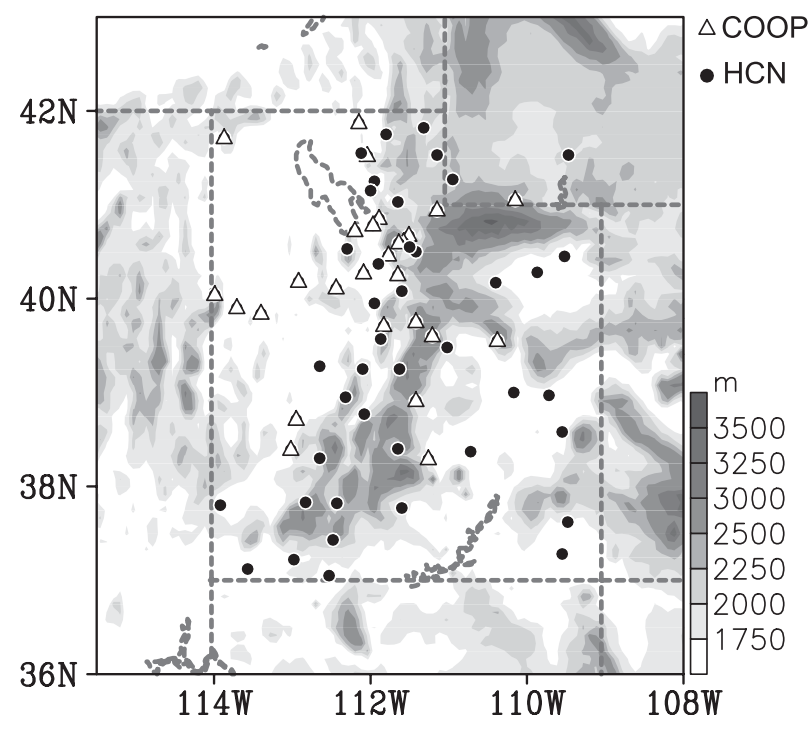

FIG. 1. Topography and station distributions of HCN (dots) and COOP stations (triangles) within Utah, including some in southwestern Wyoming.

\section{Date resources/evaluation and methods}

\section{a. Data sources}

Datasets used in this study comprised surface observations and global reanalyses. Surface observations included the National Weather Service (NWS) Cooperative Observer Program (COOP) stations and COOP-based gridded datasets. The station record came from two sources: 1) those used in the U.S. Historical Climatology Network (HCN), which have been quality controlled (Karl et al. 1990), and 2) those having at least a 95\% observation record and having operated consecutively from 1950 onward (Moller and Gillies 2008; records of these COOP stations are available for download online at the Utah Climate Center's website http:// climate.usurf.usu.edu/products/data.php). The locations of these stations are displayed in Fig. 1. Clearly the stations are not evenly distributed; rather, most are located along the Wasatch Range (north-south orientation). Therefore, objectively utilizing interpolated gridded datasets becomes a useful resource and one that extends the geographical coverage of climate information. For this reason, we made use of three gridded daily precipitation and temperature datasets: 1 ) that of Hamlet and Lettenmaier (2005), which used only HCN stations over the period 1915-2003; 2) that developed by Maurer et al. (2002), which used COOP stations over the period of 1949-2005; and 3) the same Maurer et al. data but updated to 2010, which incorporated an adjustment on the timing of the record (i.e., if a meteorological station has a time of observation before noon, the 
precipitation is assigned to the prior day, otherwise no adjustment is made, as documented in the NWS Colorado Basin River Forecast Center at http://www. cbrfc.noaa.gov/devel/vic_8d_forc/). All three datasets were projected onto a $1 / 8^{\circ}$ grid mesh by utilizing a hydrological model; for further details one is referred to Maurer et al. (2002). Also of note, and for reasons that will be shown in the ensuing data evaluation (section 2c), only the updated Maurer et al. (2002) data were used in our analysis. In addition, for the purposes of evaluation, we acquired the National Oceanic and Atmospheric Administration (NOAA) Climate Prediction Center's (CPC's) daily precipitation analysis at a $1 / 4^{\circ}$ resolution (Chen et al. 2008) and the University of Delaware's monthly precipitation data at a $12^{\circ}$ resolution (Legates and Willmott 1990), both of which are station-based gridded datasets. Since the winter of 1949 was extremely wet and the data quality questionable (A. Wood 2011, personal communication), all trend analyses start at 1950. It is, however, important to note that the COOP station data and the Maurer et al. (2002) gridded products had not been corrected for nonclimatic effects (e.g., heat island bias, measurement time changes, and instrumentation changes).

For the analysis of other relevant meteorological variables, the following four global reanalysis datasets were analyzed: 1) the National Centers for Environmental Prediction (NCEP)-National Center for Atmospheric Research global reanalysis covering the period 1948-present (NCEP1; Kalnay et al. 1996); 2) the NCEP-Department of Energy reanalysis 2 for 19792009 (NCEP2; Kanamitsu et al. 2002); 3 ) the 40-yr European Centre for Medium-Range Weather Forecasts (ECMWF) global reanalysis (ERA-40) for 1958-2002 (Uppala et al. 2005); and 4) the ERA-Interim reanalysis for 1989-present (Uppala et al. 2008). All reanalyses had a spatial resolution of $2.5^{\circ}$, the exception of which was the ERA-Interim $\left(1.5^{\circ}\right)$. These reanalyses were averaged to daily and monthly values from their original 6-hourly time step. We also analyzed satellite-observed monthly snow cover derived from the visible channels of three platforms. The snow cover data covered the period 1972-present having a $2^{\circ}$ resolution; these data were downloaded from the National Snow and Ice Data Center.

\section{b. Rain-snow threshold temperature delineation methodology}

In precipitation climatological analyses, a rain-snow threshold (RST) temperature method is repeatedly adopted to define what portion of the precipitation has fallen as snow versus that of rain by means of measurements of surface air temperature Ts. Early experiments conducted by the U.S. Army Corps of Engineers (1956) suggested that $\mathrm{Ts}=2^{\circ} \mathrm{C}$ was a reasonable transition temperature for dividing rain from snow. Auer (1974) analyzed measurements of solid and liquid precipitation and noted that at $\mathrm{Ts}=2.5^{\circ} \mathrm{C}$, the probabilities of observing rain and snow were equal. In a more recent study, Dai (2008) used 3 -hourly weather reports and found that the phase transition from snow to rain over land occurred within a wide range of temperatures from -2 to $4^{\circ} \mathrm{C}$. Moreover, other studies (Yuter et al. 2006; Lundquist et al. 2008; Jones 2010) have noted that a $1^{\circ} \mathrm{C}$ wetbulb temperatures around $\pm 1^{\circ} \mathrm{C}$ were reasonable limits within which to determine mixed phases of snow and rain.

Such RST methods are particularly useful, when used with gridded data, to provide spatial fields of snow and rain. For instance, Yang et al. (1997) adopted Auer's method using climate model output in which they applied a single RST value Ts of $2.2^{\circ} \mathrm{C}$ to separate snow from rain. Recently, Gillies et al. (2011b) applied a RST method to both station and reanalysis data over China and found that a Ts range between $0^{\circ}$ and $2^{\circ} \mathrm{C}$ effectively depicted the precipitation transition from snow to rain. However, in the Gillies et al. study, the RST method was applied to estimate the ratio between $S$ to total precipitation $P$, denoted as $S / P$ (Here, $S$ denotes snowfall water equivalent while SWE denotes snow water equivalent.) Another method (Knowles et al. 2006) defines $S / P$ somewhat differently (referred to as the one/ zero method), which identifies two categories of $S /$ $P$-that is, $S / P=1$ with nonzero snowfall readings, and $S / P=0$ with zero snowfall readings.

The question as to which method would be germane to Utah meant a comparison of the two $S / P$ methods. Consequently, using the COOP station records, we calculated the January-March (JFM) $S / P$ over the period 1998-2010 using both methods, and then computed the correlations and mean differences of their $S / P$. The results (Fig. 2) indicate that the correlations between the two methods (Fig. 2a) are generally high in interior Utah but decrease toward the western and southern borders. As to the mean differences (Fig. 2b), these are larger in the interior and become negative toward those stations that define the boundary of COOP measurements. We were concerned that such differences might mask the true trends in $S / P$ and therefore decided to undertake a more exacting assessment of RST for Utah.

To determine a more reasoned RST temperature for the region, we analyzed daily precipitation, snowfall (measured from snow boards), and Ts (defined as the average of maximum temperature $T_{\mathrm{MAX}}$ and minimum 
(a) correlation coefficients

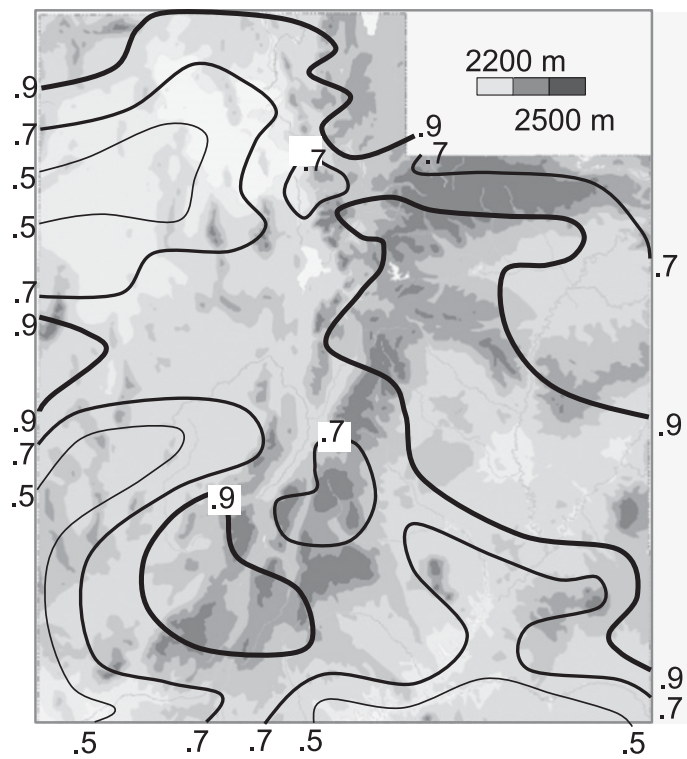

(b) mean differences (\%)

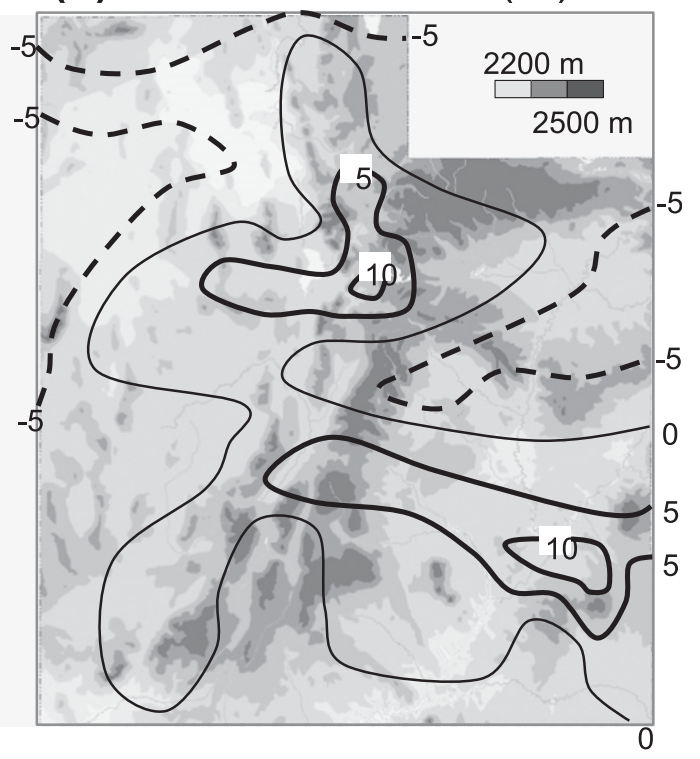

FIG. 2. Comparisons between the two $S / P$ methods (one/zero vs RST; see text) in the forms of (a) correlation coefficients and (b) difference in the means during January-March between 1998 and 2010. Contours were drawn using the COOP and HCN station data, locations of which are given in Fig. 1. Shading depicts the topography.

temperature $T_{\mathrm{MIN}}$ ), from the $\mathrm{COOP} / \mathrm{HCN}$ stations for the period 2001-07. Adoption of a post-2000 analysis was to satisfy the time that snow board observations of snowfall depth had become a routine measurement. However, such an evaluation requires daily snowfall depth to be converted into $S$; this entails a reasonable estimate of the snow-to-liquid ratio. Although the snowto-liquid ratio in the Intermountain West changes considerably event-by-event and location-by-location, the climatological range of this ratio should provide a reasonable reference point. A recent study by Baxter et al. (2005) pointed out that the snow-to-liquid ratio around Utah fluctuates between $10 \%$ and $18 \%$ with mean values of $16 \%$ in winter and $13 \%$ in spring and fall. A later study by Alcott and Steenburgh (2010), using SNOTEL stations in Utah, ascertained an average snow-to-liquid ratio of $14.8 \%$ during winter, a value they found to be consistent at both higher and lower elevations. Therefore in the estimation of $S$, we considered it reasonable to apply $14.8 \%$ snow-to-liquid ratio for the December-February period and use the $13 \%$ value for spring.

The daily ratio of $S / P$ was subsequently examined against daily mean Ts for each station, examples of such RST criteria are plotted as probability density functions in Fig. 3; these include (Fig. 3a) four stations with an elevation below $2000 \mathrm{~m}$ and (Fig. 3b) another four above $2000 \mathrm{~m}$. The results imply that, at lower elevations (Fig. 3a), mixed snow and rain generally occur at a Ts $<7^{\circ} \mathrm{C}$ whereas $S / P$ becomes $100 \%$ when Ts $\cong$ $-3^{\circ} \mathrm{C}$, although in some stations (e.g., City Creek) mixed snow and rain phases were found at $\mathrm{Ts} \cong-5^{\circ} \mathrm{C}$. The median of the RST temperature, as indicated by the probability density function of $S / P$ between $5 \%$ and $95 \%$, generally falls between $1^{\circ}$ and $3^{\circ} \mathrm{C}$. The temperatures of all stations medians below $2000 \mathrm{~m}$ averaged at $2.6^{\circ} \mathrm{C}$ (Fig. 3c), which incidentally is close to the $2.2^{\circ} \mathrm{C}$ RST Ts used in Yang et al. (1997). For stations above $2000 \mathrm{~m}$, the median RST Ts is lower, lying at $1.2^{\circ} \mathrm{C}$ (Fig. $3 \mathrm{~d}$ ). The overall decrease in the RST Ts at higher elevations echoes the observation of Dai (2008) that the elevation dependence in the RST Ts may result from snowflakes falling into warmer layers at lower elevations.

\section{c. Gridded data evaluation}

Given the fact that gridded datasets apply varying techniques to interpolate between point measurements of observed weather variables, we undertook a data consistency evaluation to establish the veracity of the gridded datasets outlined in section 2a.

\section{1) Precipitation BREAKDOWN AND ANALYsis}

We computed the horizontal distribution of linear trends for the January-March (JFM) precipitation over 
(a) Stations below $2000 \mathrm{~m}$
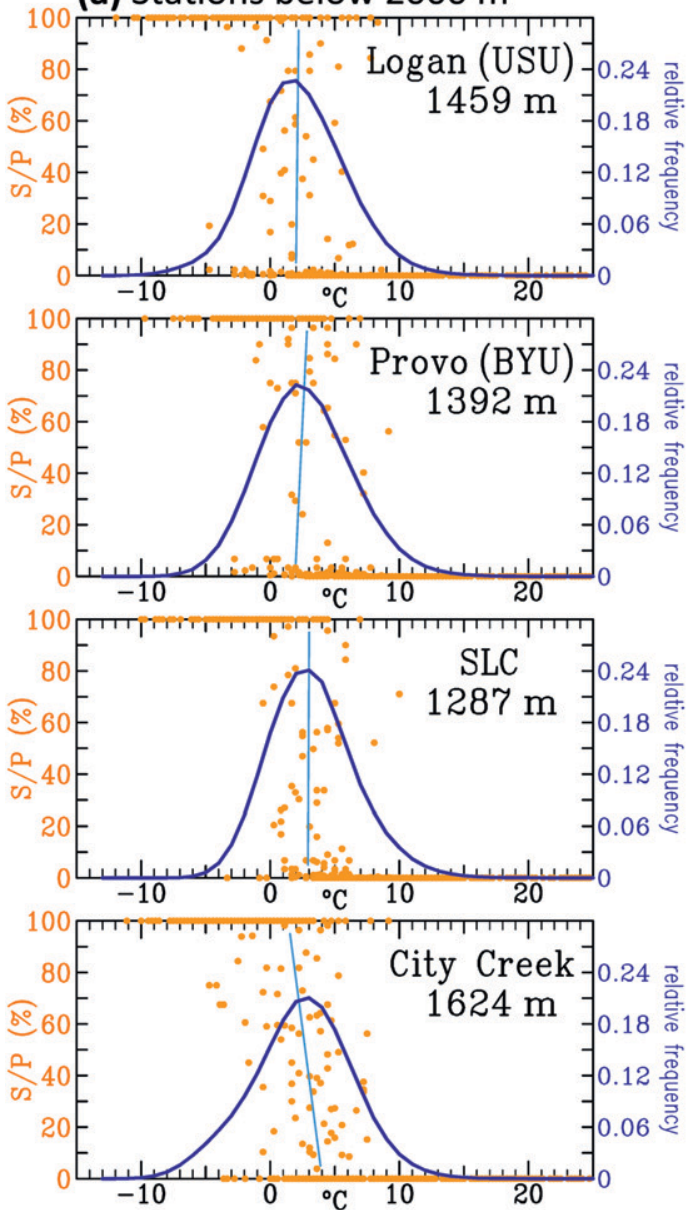

(c) Stations below $2000 \mathrm{~m}$

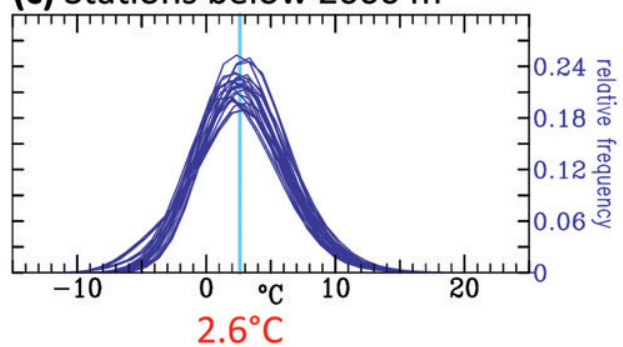

(b) Stations above $2000 \mathrm{~m}$
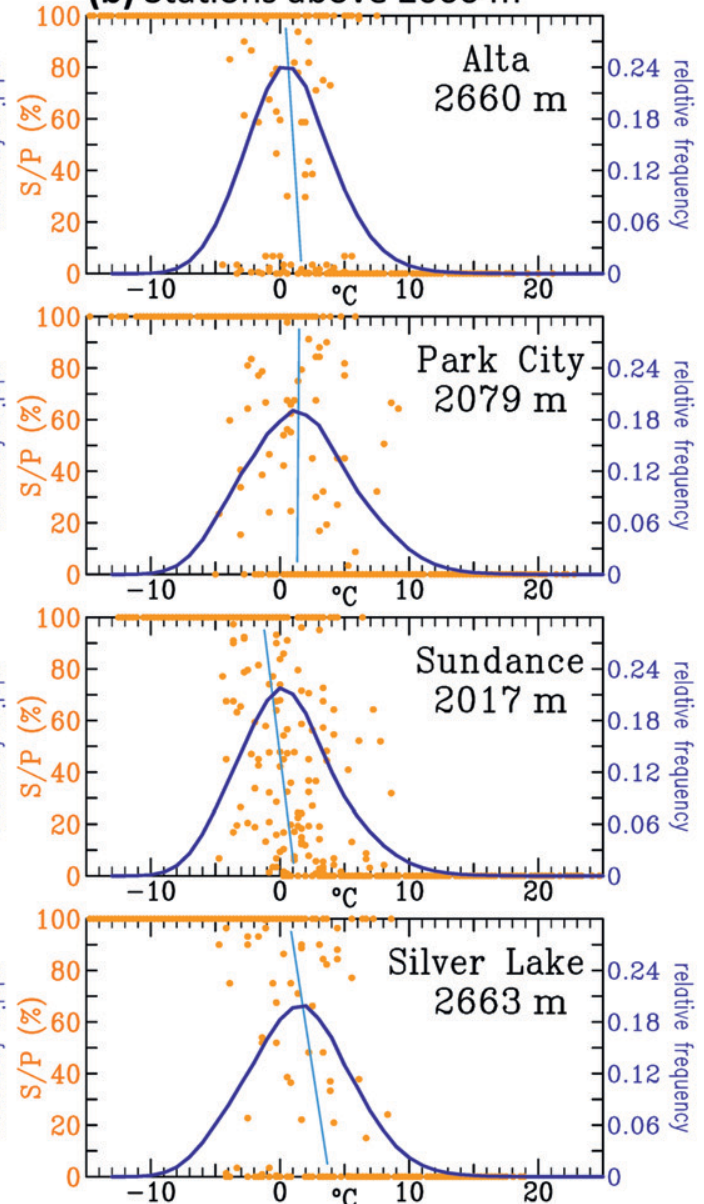

(d) Stations above $2000 \mathrm{~m}$

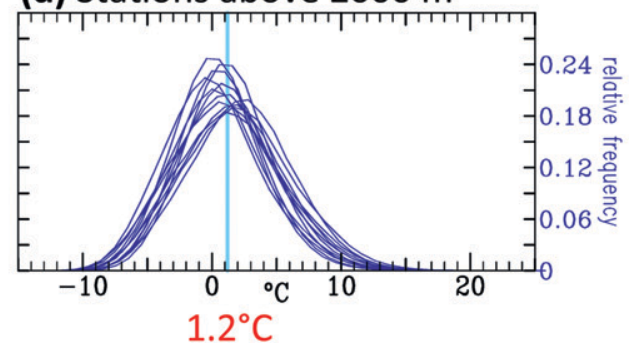

FIG. 3. Scatter diagrams of daily temperature ( $x$ axis) vs $S / P$ ( $y$ axis) from 2001 to 2007 at (a) four random stations under $2000 \mathrm{~m}$ and (b) four random stations above $2000 \mathrm{~m}$, overlaid with the probability density function (dark blue line) and linear trend (light blue line) for scatters within the 5\%-95\% range. Station name and elevation are noted in the top-right corner of each panel. (c),(d) Probability density functions of all (40) stations analyzed below and above $2000 \mathrm{~m}$, respectively, with the median temperature in red. Here, USU means Utah State Univesrity, BYU is Brigham Young University, and SLC is the Salt Lake City International Airport.

the 1950-2003 time period. All trends were calculated from least squares linear regression, applied with the minimum absolute deviation algorithm, which is designed to minimize any sensitivity to outliers in the dataset. Significance testing was based upon the Student's $t$ distribution. Figure 4 presents the plotted 5-yr trend patterns of the five gridded datasets: Hamlet and Lettenmaier (2005)—“Hamlet05" (Fig. 4a); Maurer et al. (2002) - "Maurer02" (Fig. 4b); updated Maurer et al. data-"Maurer02+" (Fig. 4c); CPC $1 / 4^{\circ}$-resolution data (Fig. 4d); and University of Delaware $1 / 2^{\circ}$-resolution data (Fig. 4e), with the inclusion of Fig. 4f station 

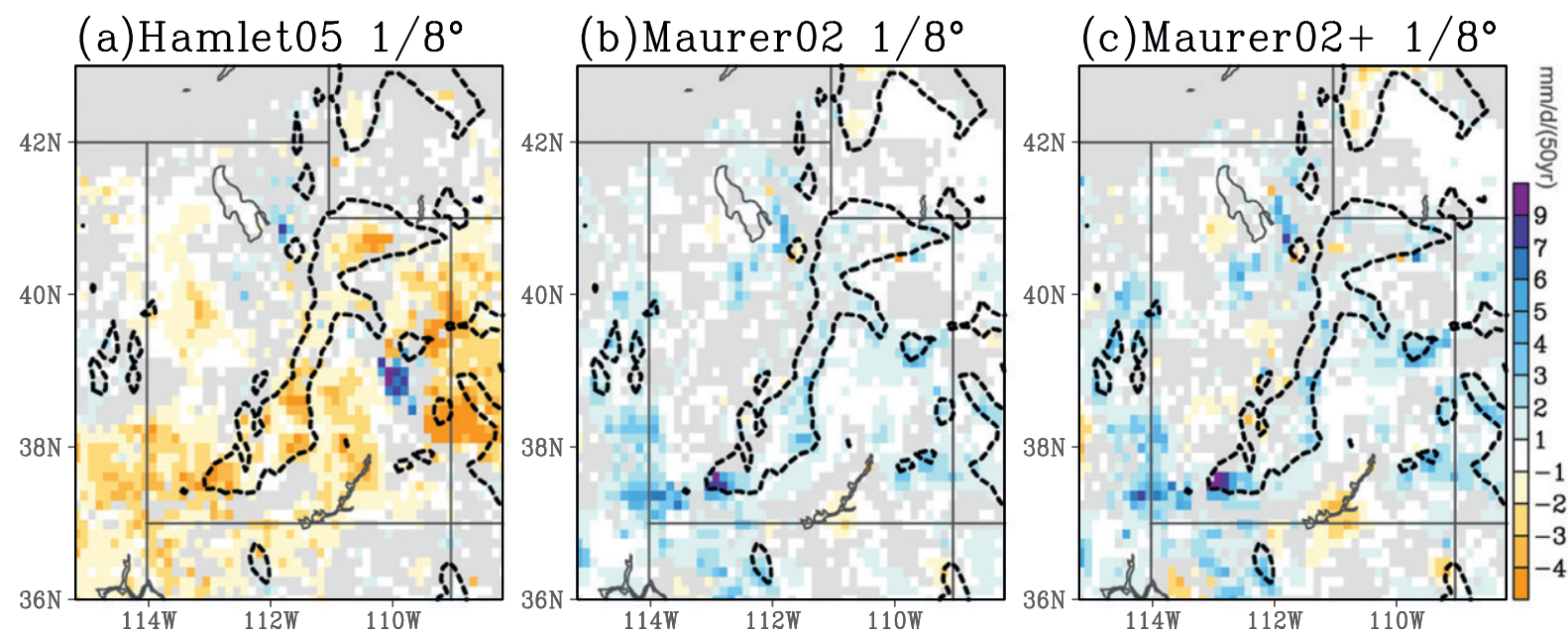

(d)NOAA CPC $1 / 4^{\circ}$

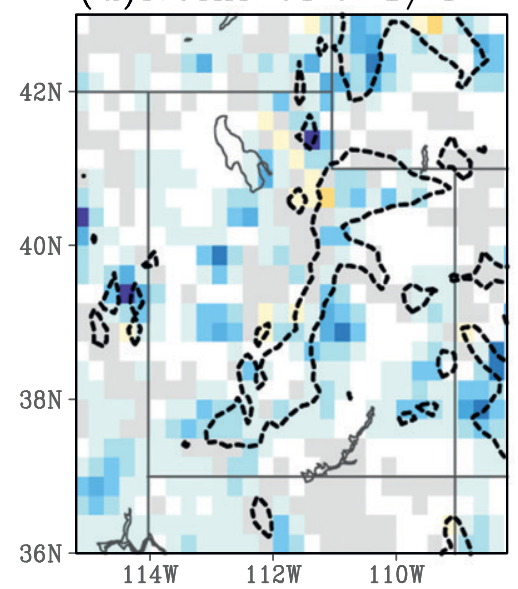

(e)Delaware $1 / 2^{\circ}$

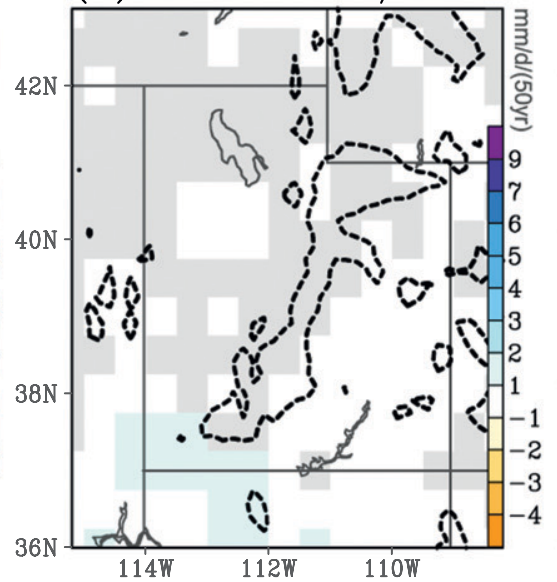

(f)COOP/USHCN
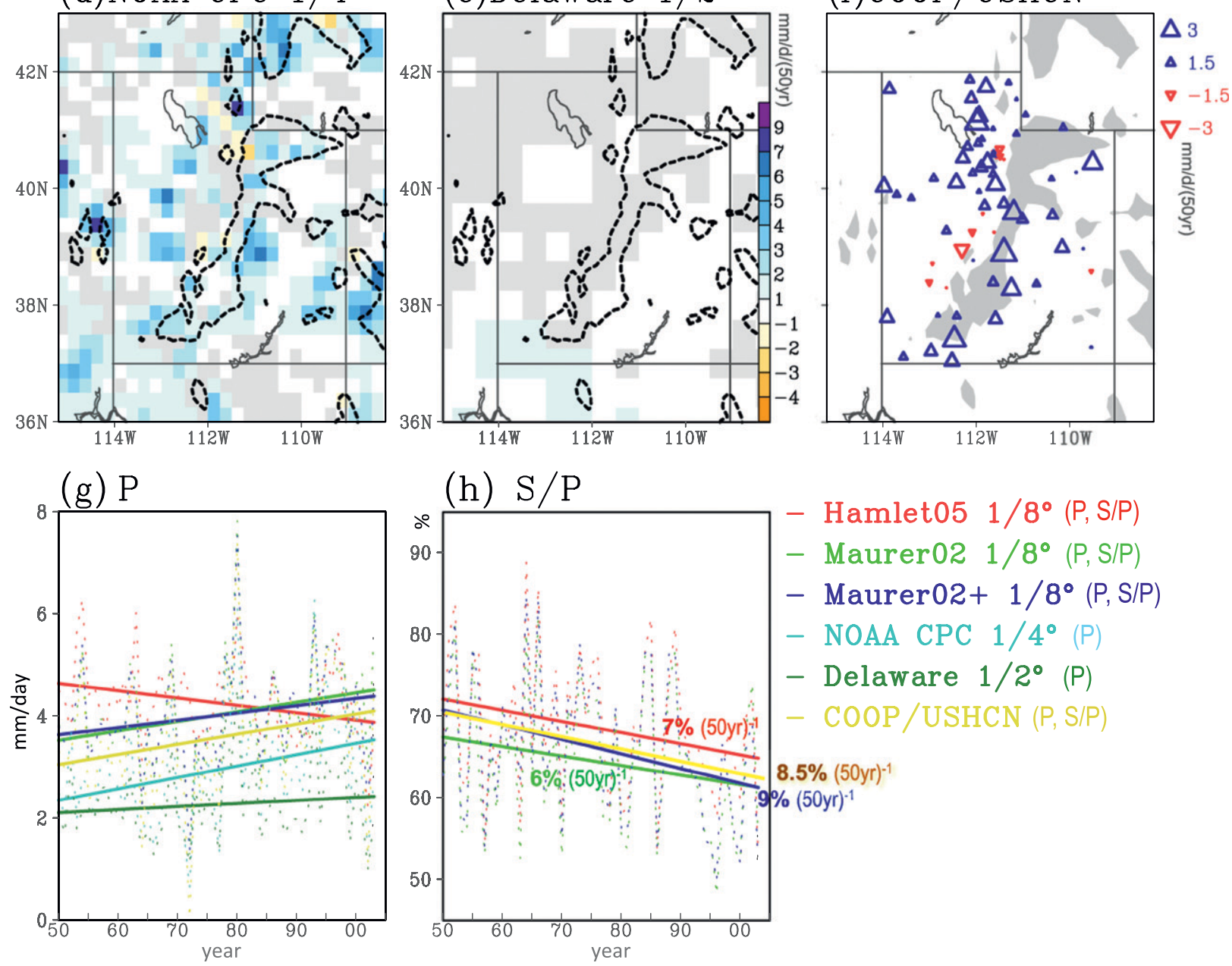

FIG. 4. Horizontal distributions of the JFM precipitation linear trends of (a) Hamlet05, (b) Maurer02, (c) Maurer02+, (d) NOAA CPC, (e) University of Delaware, and (f) COOP/HCN stations for the period 1950-2003. Gray areas in (a)-(e) indicate insignificant values; dashed contours and gray shadings in (f) outline the elevation at $2200 \mathrm{~m}$. In (f), blue upward triangles indicate increasing trends while red downward triangles indicate decreasing trends. (g),(h) Precipitation and $S / P$ (dotted lines) and their linear trends (thick solid lines) over Utah; the slopes are indicated alongside the trends. Color codes are explained to the right of $(\mathrm{h})$. 
observations from the $\mathrm{COOP} / \mathrm{HCN}$ network; areas below the significance level of 0.05 are shaded in gray [except in Fig. 4f where the gray shading indicates terrain). In all the datasets, with the exception of Hamlet05, there exists a consistent upward trend in the winter precipitation that is also consistent spatially. The spatial trend is also echoed in the average precipitation time series over Utah (Fig. 4g), albeit with differences in magnitude over time. As noted already, the Hamlet05 trend runs contrary to all the others. Clearly, something is amiss that requires investigation, especially since the trend runs counter to the actual observations themselves (cf. Fig. 4f). However, it does not behoove us to speculate upon the inconsistency here but only to reflect upon it.

\section{2) $S / P$ BREAKDOWN AND ANALYSIS}

As per our analysis for Utah in the delineation of snow versus rain, we applied either 2.6 or $1.2^{\circ} \mathrm{C}$ RST temperatures for grid points below or above $2000 \mathrm{~m}$ using the $1 / 8^{\circ}$ digital elevation model from the United States Geological Survey (Bliss and Olsen 1996) to assign elevation. In this case, (Fig. 4h) all datasets demonstrated a declining tendency in $S / P$; this echoes the observation by Knowles et al. (2006) that the precipitation trend is not a deterministic factor in the $S / P$ trend. Maurer02+ exhibits a stronger decline than Maurer02, which in turn is closer to the trend of the COOP/HCN network. Given this general agreement coupled with an extended data period of record, Maurer02+ was selected for the ensuing analysis. A recent study by Guentchev et al. (2010) also concurs with our result and subsequent decision, that is, that Maurer02+ data is suitable for trend analysis.

\section{d. Weather pattern identification}

Although an overall increase in the winter precipitation over Utah has been published (e.g., Regonda et al. 2005; Knowles et al. 2006), it is unclear how such an observed increase and a changing precipitation regime (i.e., snow versus rain) is linked to any circulation change at larger scales. Therefore, we undertook an examination of the change in precipitation from an all-together different perspective-one that encompassed weather patterns and circulation anomalies. Winter precipitation events in Utah (and much of the Intermountain West) result from specific weather patterns. The two most common weather patterns include the following: Pacific fronts associated with approaching troughs (Hobbs et al. 1980; Colle et al. 1999; Shafer and Steenburgh 2008) and zonal/anticyclonic patterns that interact with the mountains that are supplied by moisture via the subtropical jet (e.g., Colle and Mass
1995). These weather patterns are recognizable through synoptic analysis of the wind and geopotential height fields. Furthermore, the NWS Salt Lake City office has developed two general forecasting guidelines for the occurrence of precipitation. The guidelines are classified as follows.

1) Class 1: Conditions that pertain to precipitationhere the mean $850-500-\mathrm{mb}$ relative humidity is at least $80 \%$ and upward motion (output from forecast models) must be present at the 500-mb level covering at least one-third of the state.

2) Class 2: Conditions that pertain to snowfall-same as class 1 , but that the $700-\mathrm{mb}$ temperature must fall below $-8^{\circ} \mathrm{C}$ on the particular day (J. Steenburgh 2008, personal communication).

The synoptic conditions that initiate either precipitation in class 1 or 2 generally occur with either an approaching trough system or a weak ridge (diverted subtropical jet) both of which are identified by examination of the 500-mb geopotential height field over Utah (L. Dunn 2010, personal communication). Therefore, by reviewing the NCEP1 reanalysis at (i) the daily mean geopotential height at $700 \mathrm{mb}$, (ii) the wind and vertical velocity fields at $500 \mathrm{mb}$, (iii) the mean relative humidity between 850 and $500 \mathrm{mb}$, in conjunction with (iv) the 700 -mb isothermal field, we manually tracked and categorized all synoptic events as trough/subtropical jet types that had "potential" for precipitation or snowfall over the time period 1950-2009.

In summary then, the combined trough-type and subtropical jet-type patterns accounted for $93 \%$ of cumulative statewide precipitation during January-March from 1950 to 2009 . The remaining $7 \%$ was presumably associated with more localized forcing such as orographic precipitation that happens even when relative humidity is lower than the $80 \%$ criterion.

\section{Results}

\section{a. Precipitation regime change}

\section{GRIDDED DATA CLIMATOLOGY}

An initial climatological analysis of the Maurer02+ dataset, using the RST Ts of $2.6^{\circ} / 1.2^{\circ} \mathrm{C}$, Fig. 5a presents the horizontal distribution of $S / P$ in winter (JanuaryMarch). Areas with an $S / P$ ratio larger than $50 \%$ are predominately distributed along the Wasatch Range and surrounding mountain ranges (outlined by dashed contours), whereas the Salt Flats, southwestern and eastern Utah, generally received precipitation that contained less than $50 \%$ as snowfall. Figure $5 \mathrm{~b}$ is a plot of the monthly distribution of $S / P$ averaged over Utah, 

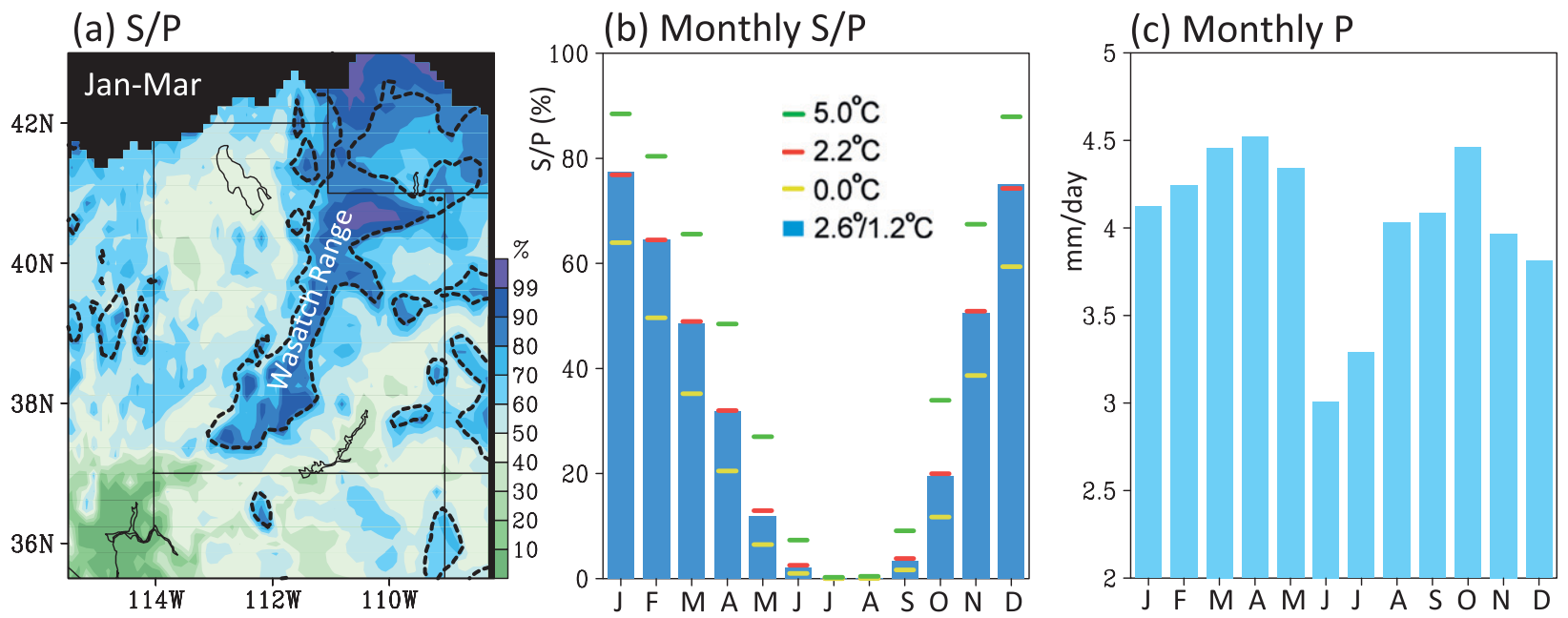

FIG. 5. (a) The January-March snow-precipitation ratio; gray dashed contours outline the elevation of $2200 \mathrm{~m}$; black denotes no data. (b) Monthly $S / P$ averaged over Utah determined by the RST Ts of $2.6^{\circ} / 1.2^{\circ} \mathrm{C}$ (histogram) overlaid with different RST settings (horizontal color sticks). (c) Monthly precipitation (1950-2010 mean) from all grid points within Utah. Data source is Maurer02+.

overlaid with $S / P$ estimated from a range of RST Ts: $2.2^{\circ}, 0^{\circ}$, and $5^{\circ} \mathrm{C}$-serving as a sensitivity test. The $0^{\circ}$ and $5^{\circ} \mathrm{C}$ values represent respectfully, the freezing point and an "extreme" value that is well above $3.8^{\circ} \mathrm{C}$ for nonnegligible snowfall over land (Dai 2008). Although temperatures between $0^{\circ}$ and $5^{\circ} \mathrm{C}$ result in an approximately $20 \%$ difference in $S / P$ during the cold season, they produce an $S / P$ distribution similar to that produced by $2.2^{\circ}$ and $2.6^{\circ} / 1.2^{\circ} \mathrm{C}$. Meanwhile, monthly precipitation in Utah (Fig. 5c) reveals a semiannual distribution that, when compared to the annual distribution in $S / P$ (Fig. 5b), suggests that the predominant snowfall season falls within the months of November-March. A characteristic such as this has implications on the divergent trends between winter precipitation and spring snowpack, which will be discussed further later.

Linear trends in monthly $S / P$ over Utah during 1950 2010 are shown in Fig. 6a. The declining trends in $S / P$ are most pronounced in the months January-May and are significant at the $95 \%$ confidence level. A weak decline in late fall is also observed. The trends in estimated snowfall (Fig. 6b) reveal a rather random pattern throughout the year with a significant increase in February (June is also significant but $S / P$ is fairly small). Trends in estimated rainfall (Fig. 6c) indicate a significant increase that peaks in spring and fall. Noteworthy are the results derived through the use of different RST Ts between $0^{\circ}$ and $5^{\circ} \mathrm{C}$, which yielded a generally consistent seasonal pattern with those derived from $2.6^{\circ} / 1.2^{\circ} \mathrm{C}$. It appears that only the January-March period exhibits $S / P$ trends that are significant at all RST Ts (Fig. 6a), although in February the trend at $5^{\circ} \mathrm{C}$ is only marginally significant. Meanwhile, trends in total precipitation (Fig. 6d) reveal significant increases in most of the months except November-January; this echoes the fact that Utah is situated in the transition boundary between increased spring SWE in the southwestern United States and decreased SWE in the Northwest (e.g., Regonda et al. 2005). Trends in daily maximum (Fig. 6e) and minimum (Fig. 6f) temperatures indicate that surface warming over Utah has been significant throughout the year, despite the last four months of the year exhibiting a cooling trend in $T_{\mathrm{MAX}}$.

Spatial distributions of observed change in the variables corresponding to Fig. 6 are shown in Fig. 7 as linear trends at each grid point for the winter season (JanuaryMarch). For $S / P$ (Fig. 7a), areas with a major decrease are mostly distributed at lower elevations. The Wasatch Range (outlined by dashed contours) exhibits generally weaker changes in $S / P$. The distribution of the snowfall trends (Fig. 7b) shows an overall decrease along the western side of the Wasatch Range and an overall increase on the eastern side, a feature undocumented by previous studies that used station data. Trends in rainfall (Fig. 7c) reveal a widespread increase at lower elevations in southern Utah, and a stronger increase over the windward (western) side of the mountains in northern Utah. Trends in total precipitation (Fig. 7d) are basically a reflection of the estimated rainfall. The tendency in $T_{\text {MAX }}$ (Fig. 7e) reveals that warming has mostly occurred around surrounding mountain ranges, and this corresponds to the declining $S / P$ (Fig. 7a). Trends in $T_{\text {MIN }}$ (Fig. 7f) depict substantial warming closer to and over the mountain ranges and are particularly prominent throughout southeastern Utah. In terms of degree of change over the period, $T_{\mathrm{MIN}}$ surpasses that of 
Estimated

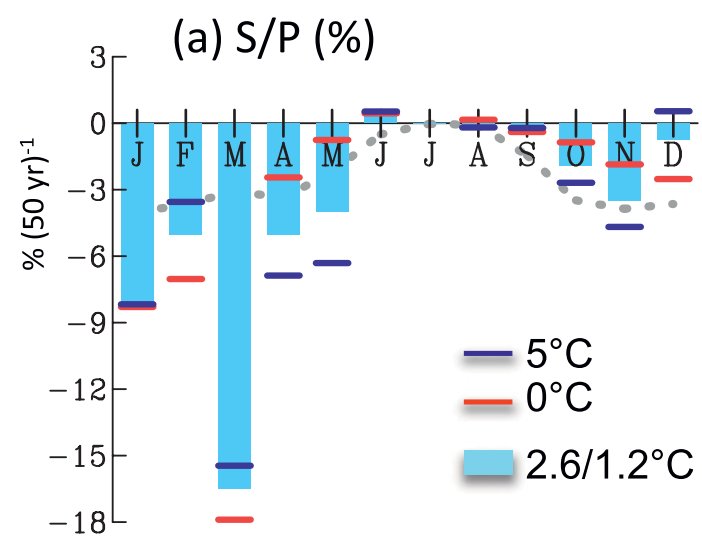

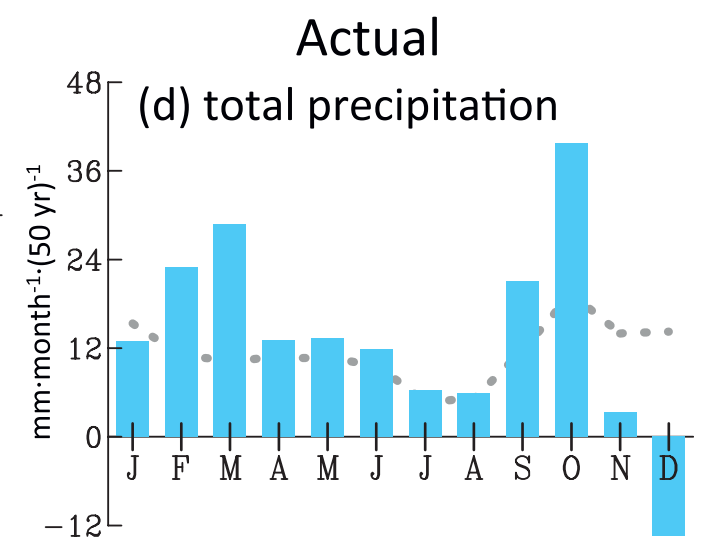

(e) $T_{\text {MAX }}$

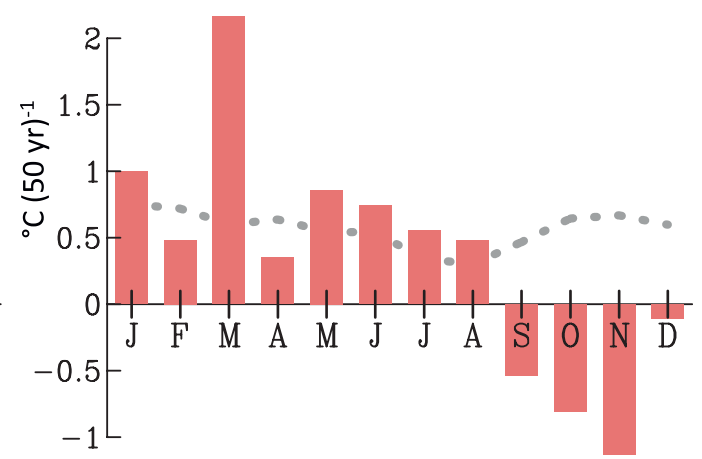

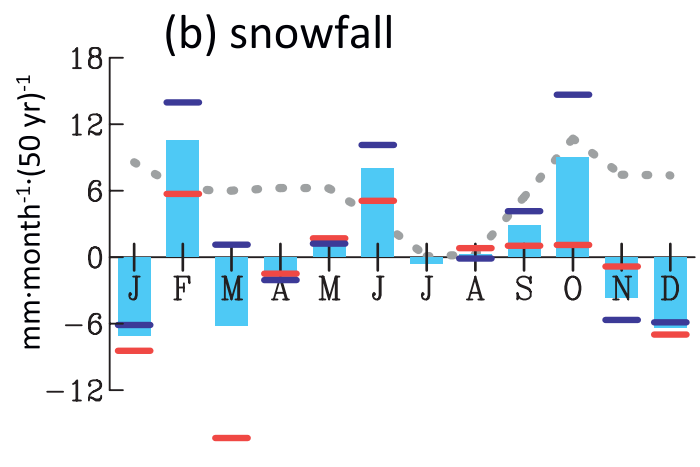

(c) rainfall

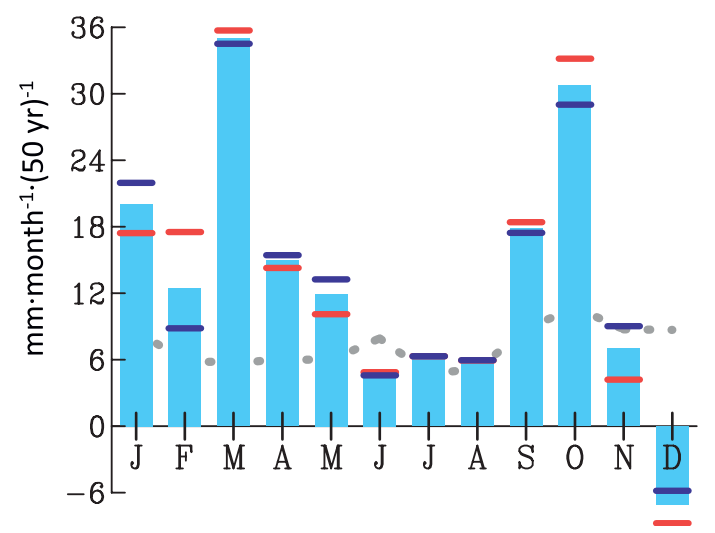

(f) $T_{\text {MIN }}$

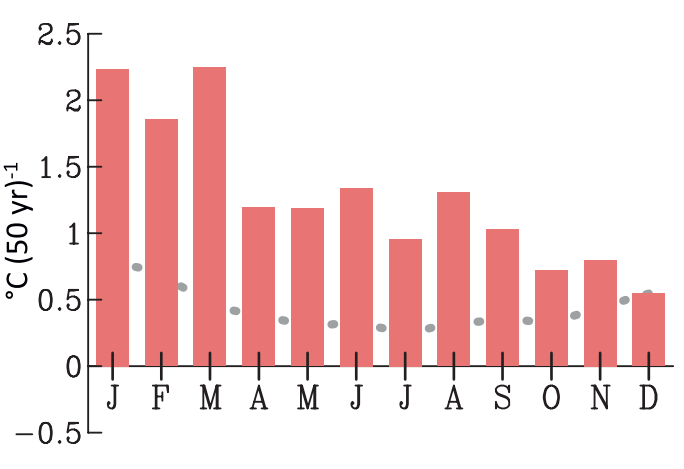

FIG. 6. Trends of monthly (a) $S / P$ ratio estimates, (b) snowfall estimates, (c) rainfall estimates, and observations of (d) total precipitation, and daily (e) maximum and (f) minimum temperatures over Utah for the period 1950-2010, derived from the Maurer02+ data. Histograms in (a)-(c) were determined by the RST Ts $=2.6^{\circ} / 1.2^{\circ} \mathrm{C}$, while horizontal color sticks indicate the RST Ts range as in Fig. 5. All trends are scaled per $50 \mathrm{yr}$. Gray dashed lines indicate the $95 \%$ confidence level (CL) based upon a Student's $t$ test.

$T_{\text {MAX }}$; this is consistent with the known phenomenon that increased moisture content in the air absorbs a greater proportion of the infrared radiation being emitted from the earth's surface at night (e.g., Dai 2006).
The trend in daily mean temperature (not shown) is not unexpectedly coherent with $T_{\mathrm{MAX}}$ and $T_{\mathrm{MIN}}$ since it is simply a factor of differential changes between the two. Likewise, daily mean temperature in southeastern 
(a) $S / P(\%)$

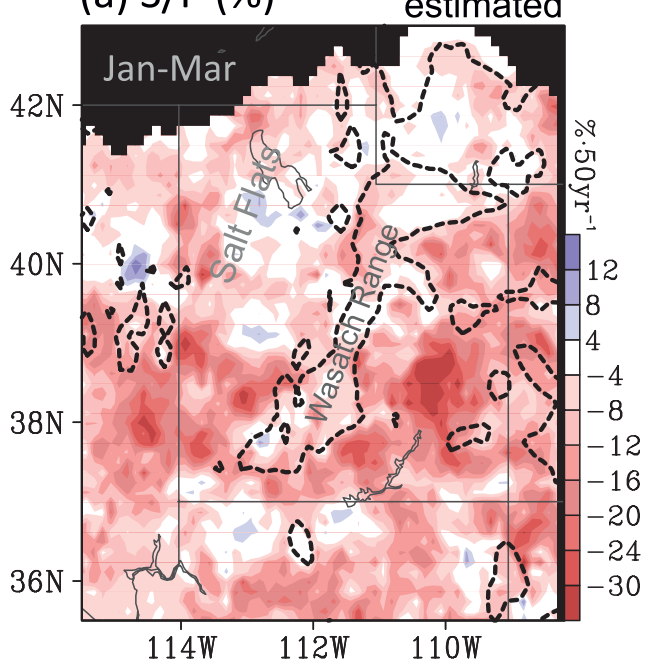

(b) snowfall
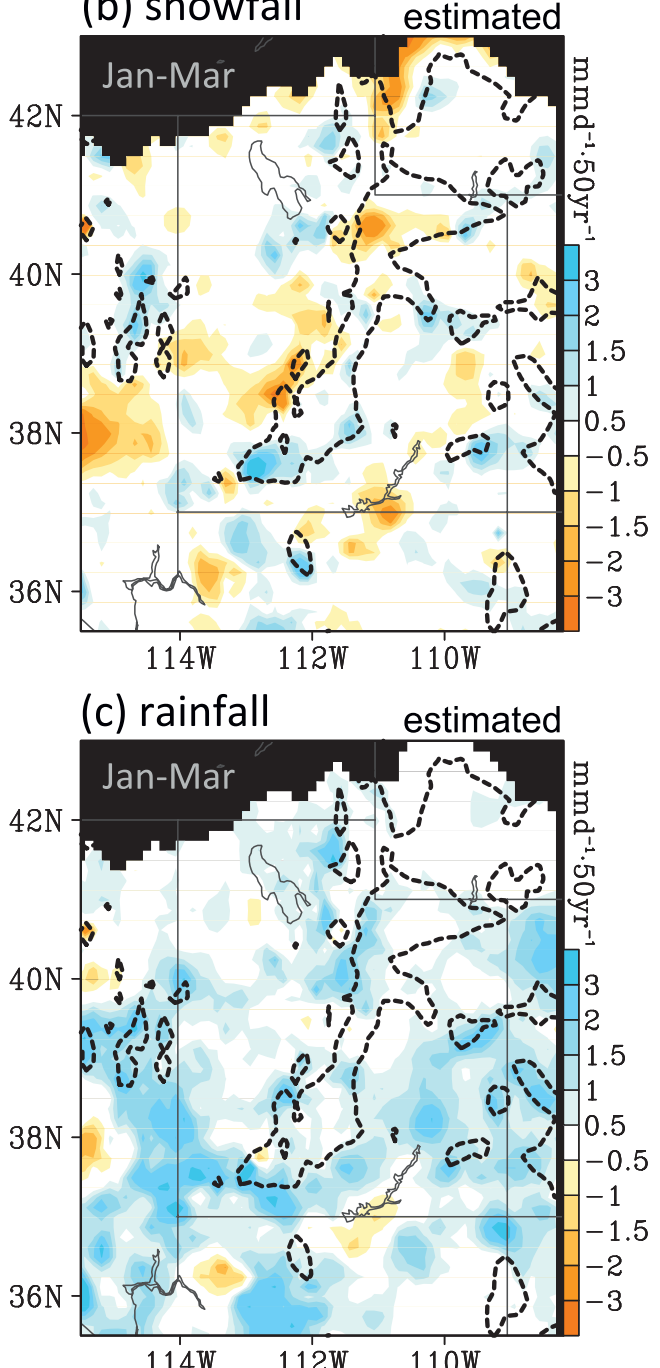

(d) Precipitation

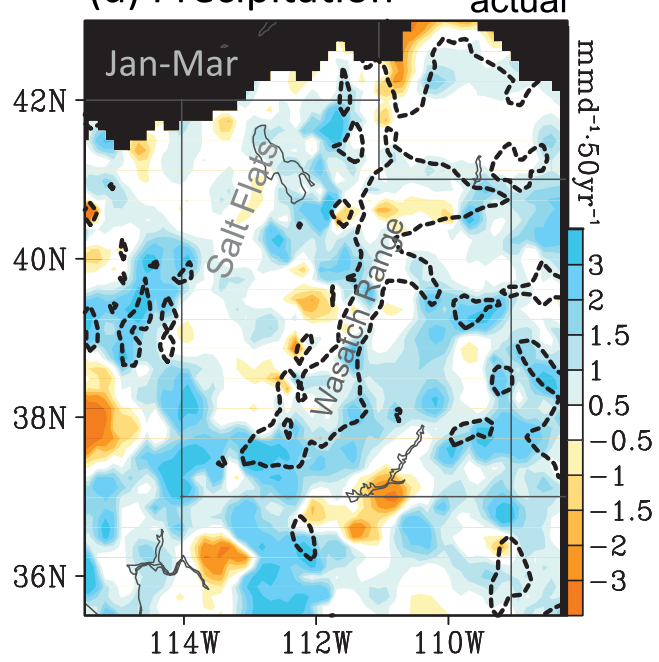

(e) Tmax

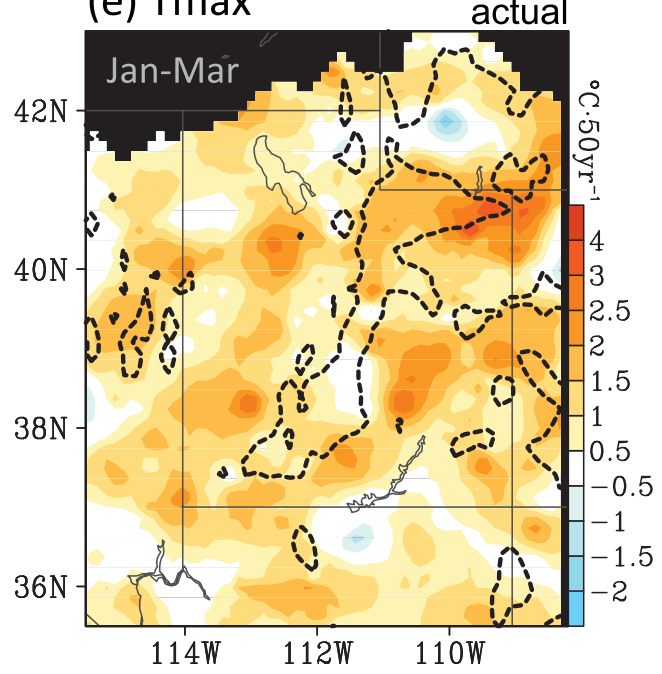

(f) $T \min$

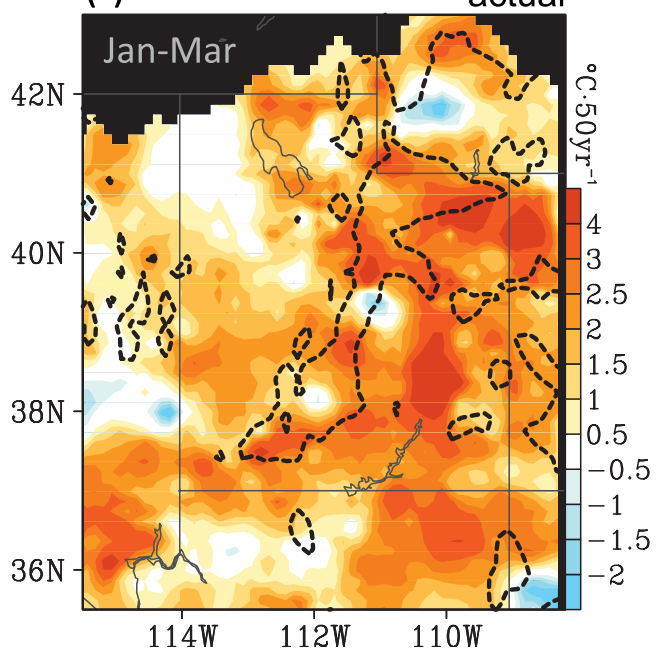

FIG. 7. Distributions of the January-March trends scaled to per $50 \mathrm{yr}$ over Utah, following the order of Fig. 6. Dashed contours outline the 2200-m elevation. (a),(d) Terrain features are indicated. Data source is Maurer02+. 
(a) Snow depth

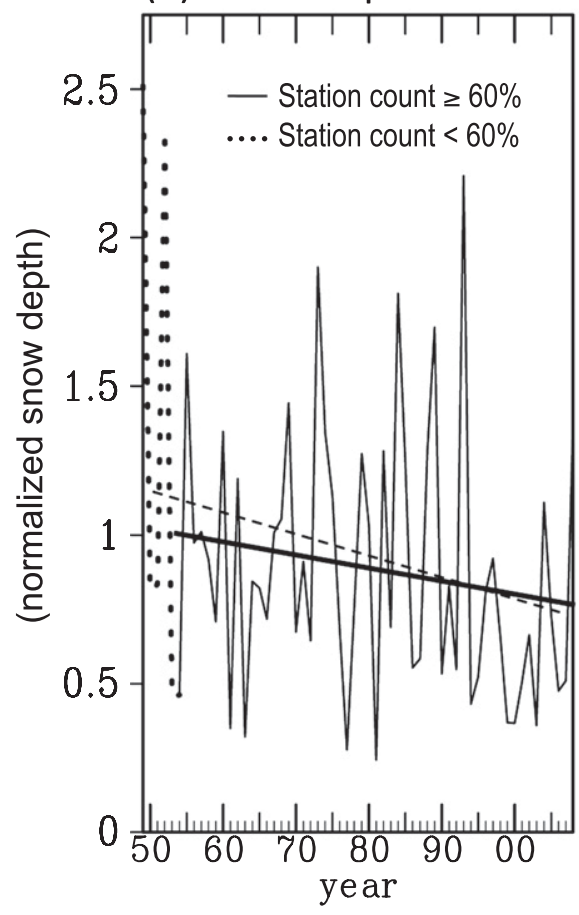

(a) Snow cover

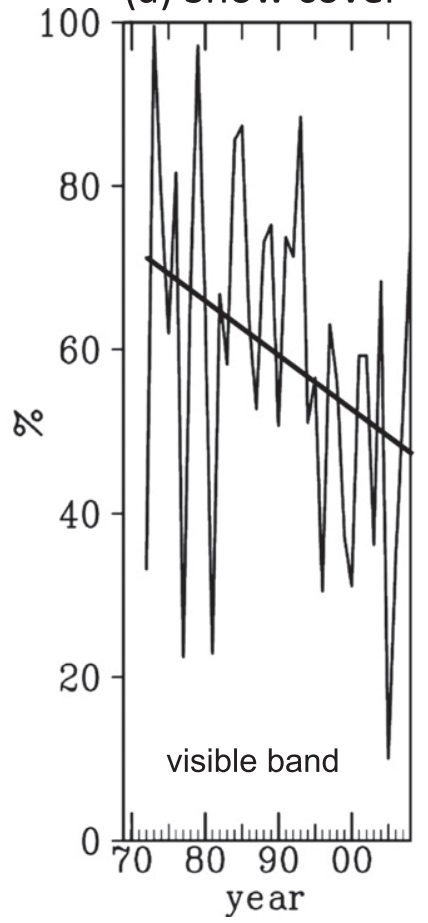

(b) Surface albedo

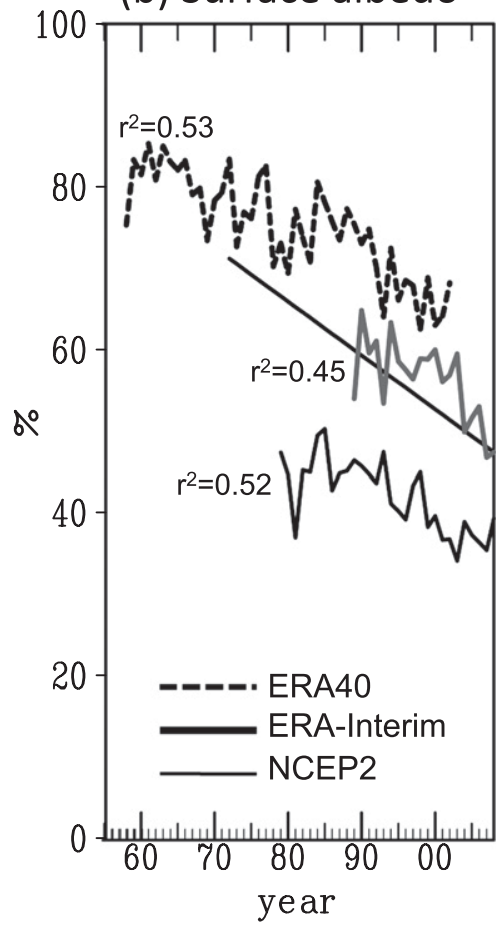

FIG. 8. January-March averages and trends in (a) snow depth from COOP stations within Utah normalized with the RMS of each station before averaging; (b) satellite-observed snow cover [from Advanced Very High Resolution Radiometer (AVHRR), Geostationary Operational Environmental Satellite (GOES), and Special Sensor Microwave Imager (SSM/I)]; and (c) surface albedo from three reanalyses over Utah, superimposed with the linear trend. In (a), the solid (dashed) trend line is for 1954-2009 (1950-2009). In (c), the solid trend line is for snow cover as in (b); $r^{2}$ values are given alongside each reanalysis.

Utah stands out as being well defined from the rest of the State.

\section{b. Station and remote sensing data}

Reference to Figs. $7 b$,d poses a conundrum in the sense that the increased winter precipitation is accompanied by a fairly widespread decline in snowpack (Mote 2006) while snowfall amounts have remained somewhat static. To try and shed some light on why this might be so, we analyzed snow depth obtained from the COOP/HCN network. The snow depth records were normalized by root-mean-square (RMS) at each station before areal averaging; this prevented the result from being dominated by high-snowfall stations. The snow depth trends were then calculated for two periods: one from all stations (1950 onward) and one from only the number of stations with snow depth observations surpassing the $95 \%$ data availability exceeding $60 \%$ of total stations (1953 onward). The result (Fig. 8a) depicts a declining trend after 1953 that is significant at the $95 \%$ confidence level. On the other hand, the declining trend since 1950 is significant at the $99 \%$ level. A firstorder response is likely through an increase in temperature (Fig. 7e,f) whereby thermodynamic processes like sublimation will directly influence snow depth even though snowfall has not changed over time. Another factor resides in the fact that rain is usually accompanied by high humidity resulting in vapor pressures in excess of the saturation vapor pressure over ice; this is an environment ripe for condensation (especially if it is windyturbulent). The latent heat released by condensation (at $0^{\circ} \mathrm{C}$ ) is $2500 \mathrm{~kJ} \mathrm{~kg}^{-1}$. It takes $334 \mathrm{~kJ} \mathrm{~kg}^{-1}$ to melt ice, so for every $1 \mathrm{~cm}$ (or $1 \mathrm{in}$.) of water condensation there is $7 \mathrm{~cm}$ (or $7 \mathrm{in}$.) of melt; this is an interesting and complex effect that depends on the humidity, temperature, and wind in the atmosphere that accompany the rain.

Other climate processes like the snow-albedo feedback are also at play here. Hence, we analyzed satelliteobserved snow cover averaged within the state boundary of Utah (six grid points). The result in Fig. $8 \mathrm{~b}$ depicts a persistent and pronounced declining trend from 1972 onward, suggesting that the extent of snow cover has shrunk from a $70 \%$ coverage statewide in the 1970 s to about $50 \%$ in the recent decade. Since snow cover strongly influences ground albedo, we examined surface albedo derived from ERA-40, ERA-Interim, and NCEP2, all of which incorporate and assimilate 
Examples of snowfall pattern

(a) Trough type (6 February 1969)

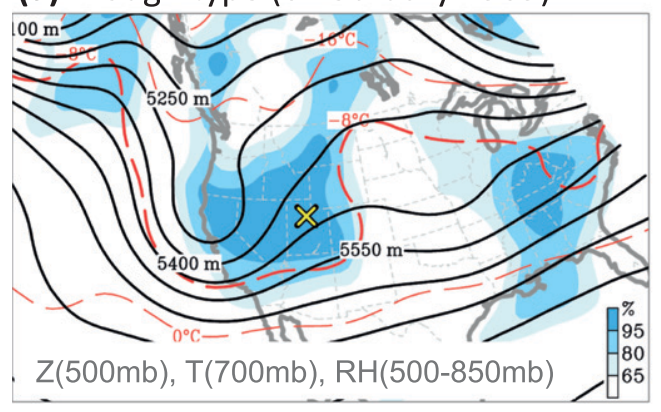

(b) Subtropical-jet type (25 January 1969)

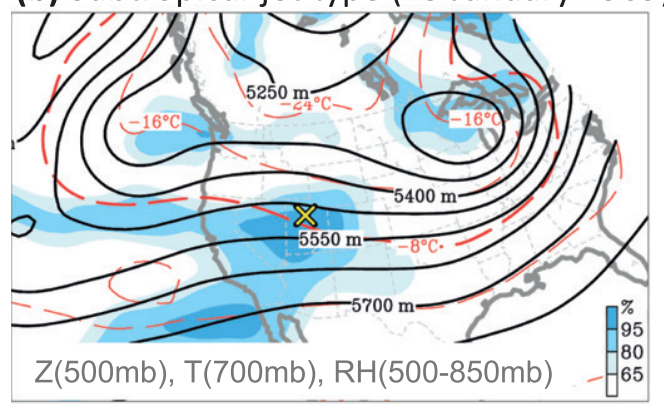

Frequency of weather systems (JFM)
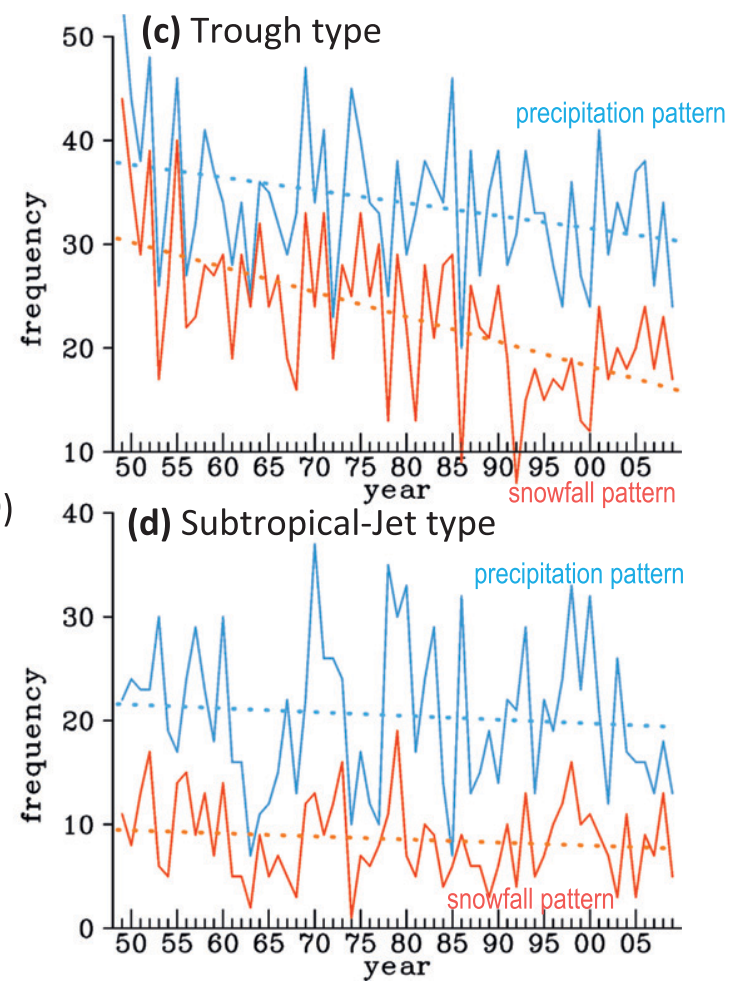

FIG. 9. The 500-mb geopotential height (black contours), 700-mb temperature (red dashed contours), and mean relative humidity between 500 and $850 \mathrm{mb}$ (shading) on (a) 6 Feb 1969 and (b) 25 Jan 1969. Salt Lake City is marked as a yellow cross. January-March total frequencies of weather systems categorized as (c) the trough-type and (d) the subtropical jet-type precipitation (snowfall) patterns are shown as blue (red) lines. Least squares trends are plotted as dashed lines; only trends in the trough type are significant at the $95 \%$ confidence level.

satellite measurements of the radiation budget. There are eight grid points within the state boundary from ERA-Interim and four from ERA-40 and NCEP2. Despite differences in the absolute values between the different reanalyses, all three reanalyses point to a persistent decrease in surface albedo over Utah after 1980 (Fig. 8c). The decline in albedo corresponds to either a shrinking snow cover extent as exhibited in Fig. 8b, a thinning snowpack as suggested in Fig. 8a, or both. Either way, the consequence is reduced reflection of shortwave radiation. Moreover, recent observations of dust initiating a change in albedo are another possible contributing factor. For instance, Qian et al. (2009) suggested that in the western United States the soot-induced snow albedo changes increase surface net solar radiation flux, hence increasing surface air temperature and reducing snow accumulation.

\section{c. Synoptic weather analysis and dynamics}

Next, we took a different tack and examined the synoptic weather conditions that induce precipitation and snowfall (a.k.a., precipitation/snowfall weather patterns). First, Fig. 9 displays two examples describing the synoptic conditions that result in precipitation and snowfall: one is coupled to the "trough type" and one coupled to the "subtropical jet type." On 6 February 1969 (Fig. 9a), a synoptic trough moved across the Pacific Northwest and induced high relative humidity conditions over Utah between 850 and $500 \mathrm{mb}$. In addition, 700-mb temperatures were well below $-8^{\circ} \mathrm{C}$. An average $4.4 \mathrm{~mm}$ in precipitation fell on the state with about $3.1 \mathrm{~mm}$ falling as snow. On 25 January 1969 (Fig. 9b), a subtropical jet-type system (i.e., the Pineapple Express) developed under a weak ridge; this system was accompanied by high relative humidity and cold temperatures at $700 \mathrm{mb}$. The event produced $10 \mathrm{~mm}$ in precipitation with $6.2 \mathrm{~mm}$ falling as snow.

To validate the synoptic analysis, we first used the historical precipitation and snowfall observations at the Salt Lake City International Airport (KSLC) to define a set of hit and miss scores: a hit meant that precipitation occurred on the day of an identified precipitation pattern, and a miss meant that (i) no precipitation was 
recorded under the weather pattern identified as a precipitation day or (ii) precipitation was recorded on a nonprecipitation day. The same approach was employed in the examination of snowfall cases. The skill score was defined by the percentage ratio of hit/(hit + miss). At KSLC, the skill score was $86 \%$ for both snowfall and precipitation patterns. A further check with a highaltitude station at Alta [8730 $\mathrm{ft}(2661 \mathrm{~m})]$ resulted in a skill score of $92 \%$ for the snowfall pattern and $85 \%$ for the precipitation pattern. Furthermore, the skill score using the gridded dataset of Maurer02+ (Fig. 10) depicts terrain dependence, where the scores are generally higher over the mountain range than at lower elevations. Nonetheless, both precipitation (Fig. 10a) and snowfall (Fig. 10b) patterns exhibit good forecast skill scores averaged to about $90 \%$ over the state, which is sufficiently high to represent precipitation and snowfall occurrences.

\section{1) WEATHER PATTERN VARIATIONS}

The time evolution of the frequency of these weather patterns was examined next. For comparison purposes the result is shown in Fig. 9 alongside two synoptic weather pattern examples. For the precipitation pattern, the trough-type frequency (Fig. 9c) reveals a declining trend that is more pronounced compared to that of the subtropical jet type (Fig. 9d). Trends are only significant in the trough-type weather pattern $(p<0.01$, under the $t$ test). For the snowfall pattern, the decline of the trough type is even stronger, having reduced 14 events over the last $50 \mathrm{yr}$. The fact that the frequency of the snowfall pattern has decreased twice as fast as the precipitation pattern lends support to the decline in $S / P$ and, as identified earlier (Fig. 8), is in line with the decreasing snow depth. On the other hand, the frequency of the rainfall pattern, (i.e., storms that produce rainfall rather than snowfall) as was inferred from the difference in trends between the precipitation and snowfall patterns, has increased by $25 \%$.

For the purposes of comparison, we accumulated precipitation for the snowfall pattern against that for the precipitation pattern. The estimated $S / P$ (Fig. 11a) reveals a declining trend of $9 \%(50 \mathrm{yr})^{-1}$, coincident with the RST-derived $S / P$ trend of $9 \%$ (Fig. $4 \mathrm{~h}$ ). Moreover, the estimated $S / P$ exhibits a steeper decline in the troughtype pattern (Fig. 11b; 15.3\%) whereas the trend in the subtropical jet type was insignificant (Fig. 11c). These findings suggest that the decline in $S / P$ is associated mostly with the trough-type weather pattern.

A particularly interesting occurrence is shown in Fig. $11 \mathrm{a}-\mathrm{a}$ noticeable persistently higher $S / P$ prior to 1977 is evident as compared to that after 1977; this is highlighted by dashed lines representing the two (a) Skill: precipitation pattern (\%)

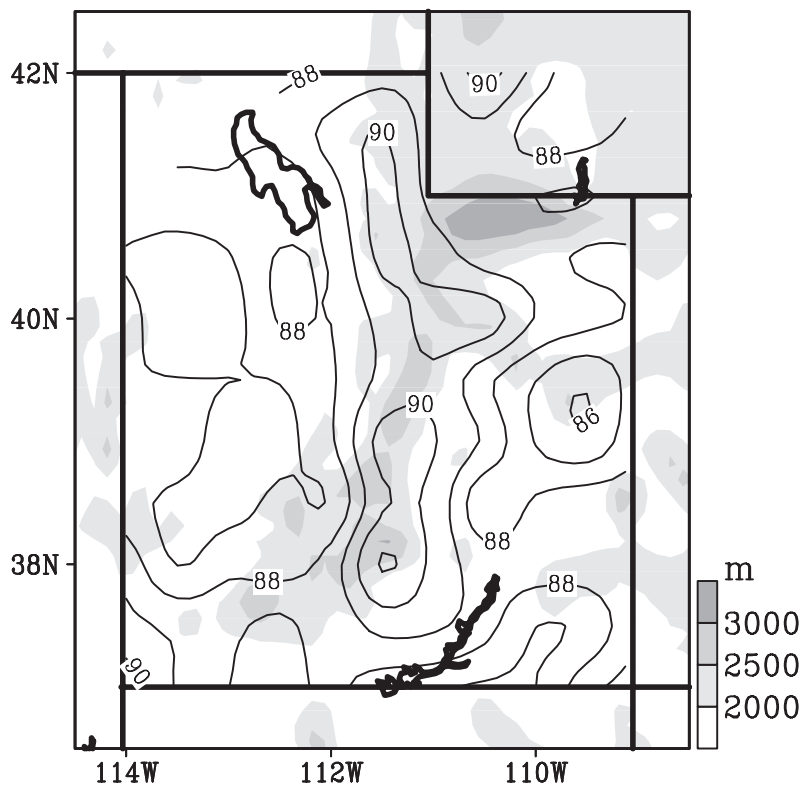

(b) Skill: snowfall pattern (\%)

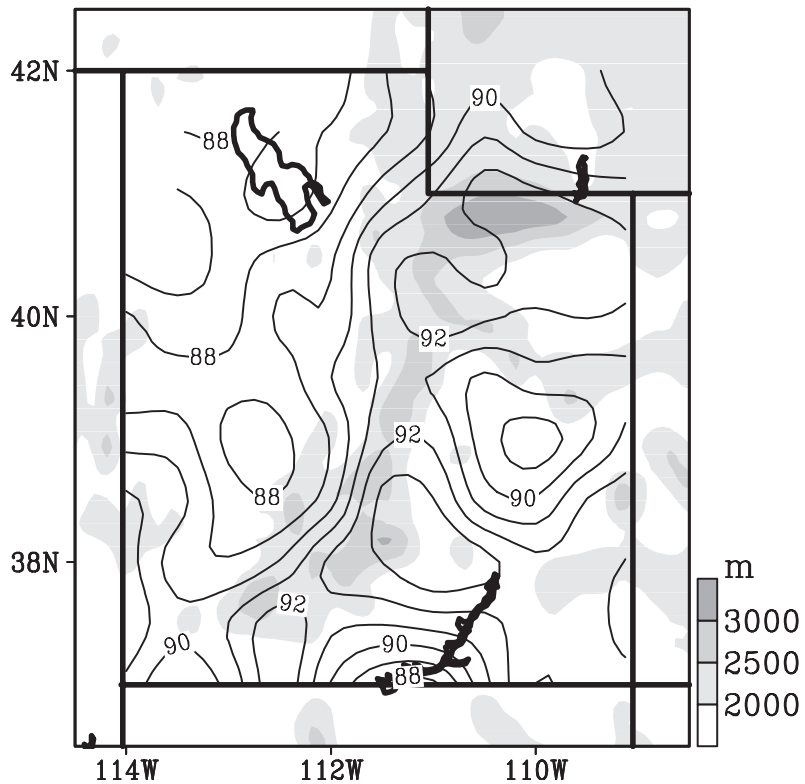

FIG. 10. Skill scores of the weather pattern identification based on Maurer02 + data during 1950-2009 for (a) precipitation pattern and (b) snowfall pattern. The snowfall is estimated from the RST Ts of $2.6^{\circ} / 1.2^{\circ} \mathrm{C}$. Shading indicates the topography.

averages. The discontinuity would appear to be reflective of the multidecadal climate regime change linked with the Pacific decadal oscillation (PDO; Mantua et al. 1997). To establish the existence of any connection, we compared the $S / P$ anomaly with the PDO index (the PDO index was obtained from the University of Washington at http://jisao.washington.edu/pdo/PDO.latest), both of 

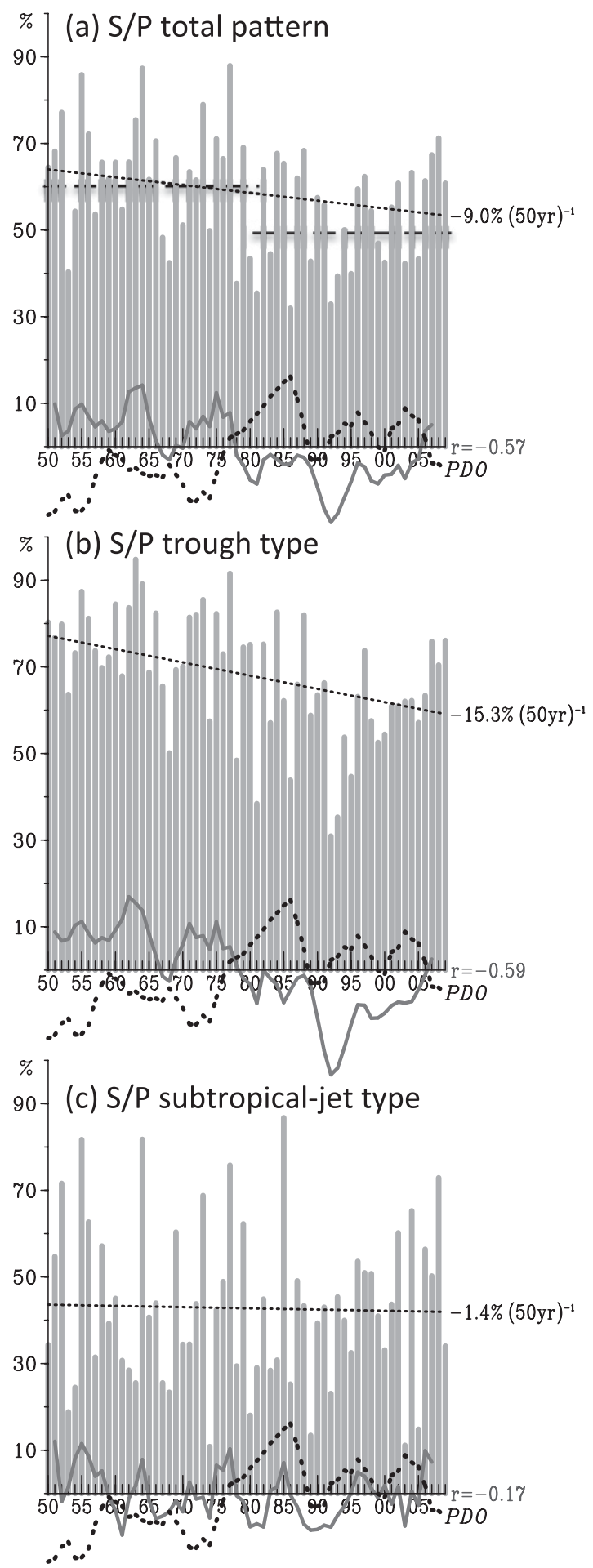

FIG. 11. January-March $S / P$ estimated from the ratio of precipitation amounts between the snowfall pattern and the precipitation pattern for (a) trough and subtropical jet types, (b) trough type, and (c) subtropical jet type with linear trends (black dotted line). Plotted at the bottom of each panel are the 5-yr running means of $S / P$ with the climate mean removed (thick gray line) and the PDO index (dotted line). The correlation coefficient $r$ between the two time series is given to the right. Data source is Maurer02+. which were computed as JFM means with a 5-yr moving average. The two time series (Fig. 11, bottom) are observed to fluctuate in an opposite manner, and this is supported by a significant correlation coefficient of $-0.57(p<0.05)$. It is therefore reasonable to purport that the $S / P$ responds to cooler temperatures over Utah during the negative phase of the PDO and warmer temperatures during the positive phase (cf. Fig. 3a of Mantua et al. 1997). Similarly, the correlation is evident and stronger in the trough-type pattern (Fig. 11b; -0.59) but is insignificant in the subtropical jet type (Fig. 11c; $-0.17)$. Only weak correlations were found between the PDO and the frequency of both types of weather systems (not shown). Two conclusions can be drawn from this analysis: 1) while the PDO's direct impact on winter precipitation in Utah is minimal (i.e., the maximum impact occurs during the PDO transitions; Wang et al. 2009a), it appears to have a direct impact on $S / P$; and 2 ) the PDO's modulation on the $S / P$ only occurs in the trough-type weather pattern. The latter may be related to the PDO's interaction with the North Pacific storm tracks (e.g., Strong and Magnusdottir 2009) from which trough-type patterns originate, but how such an influence is decoupled from the subtropical jet-type remains unclear.

What is more certain from the analysis so far is that precipitation per event has increased. For the troughtype pattern, a $14 \%$ increase in the event precipitation was observed (Fig. 12a), associated with a $25 \%$ increase in the event rainfall (Fig. 12b) and no change in the event snowfall (Fig. 12c); these support the declining $S / P$ as was shown earlier (cf. Fig. $4 \mathrm{~h}$ ). For the subtropical jet-type pattern, the event precipitation, rainfall, and snowfall (Figs. 12d-f) all reveal insignificant trends; these agree with the mild change in $S / P$ as is shown in Fig. 11c. Also noteworthy is the fact that the two types of weather patterns appear to produce a similar amount of precipitation, though the trough type apparently contributes more to the seasonal amount owing to its higher frequency (cf. Fig. 9).

\section{2) Possible Dynamics}

In considering potential dynamical processes that may have induced the precipitation changes, we computed linear trends in the synoptic conditions generated from the different composite weather patterns. Figure 13 shows the departure of the 300-mb geopotential height for the trough-type (left) and the subtropical jet-type (right) patterns, superimposed with trends in 700-mb temperature (Fig. 13a), 700-mb specific humidity (Fig. $13 \mathrm{~b}$ ), and 500-mb vertical velocity (Fig. 13c). A midtropospheric warming is present in the composite trough pattern over the northwestern United States and western 
trough type

(a) event precipitation

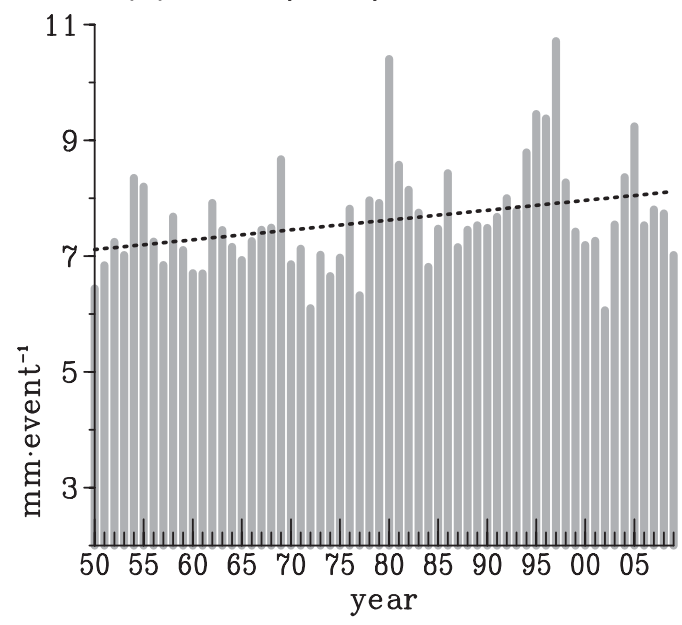

(b) event rainfall

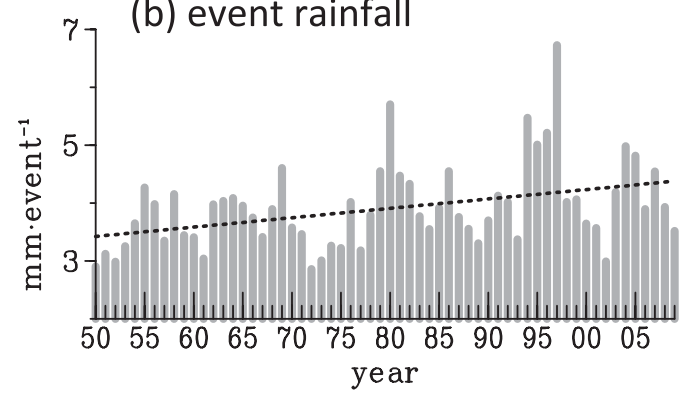

(c) event snowfall

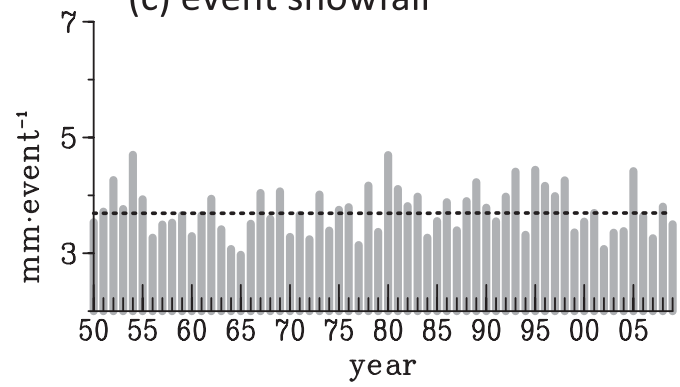

subtropical-jet type

(d) event precipitation

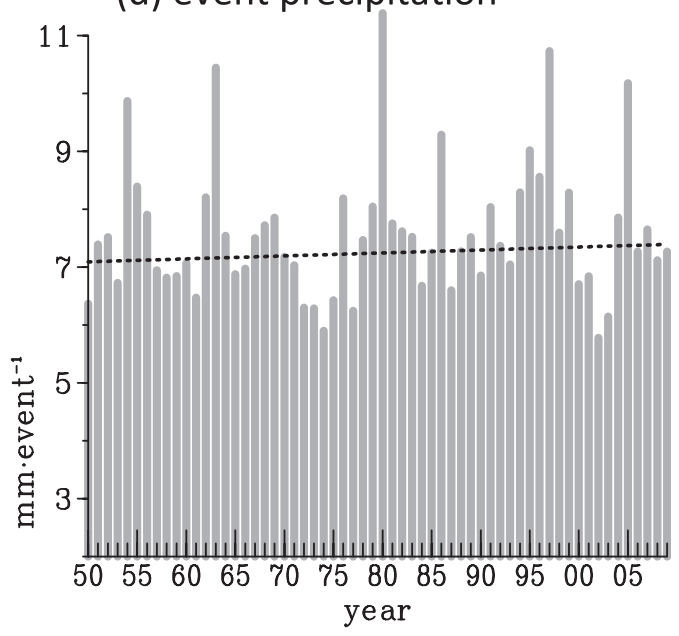

(e) event rainfall

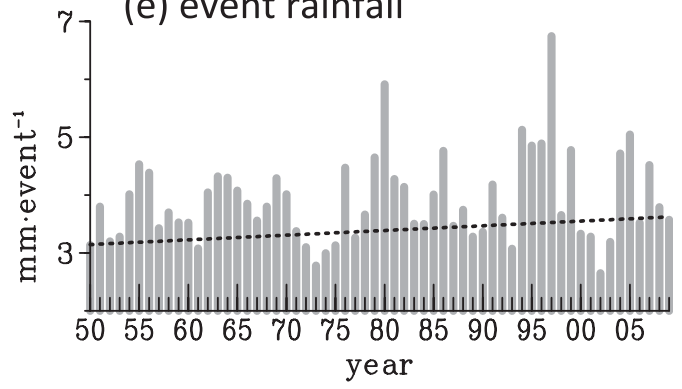

(f) event snowfall

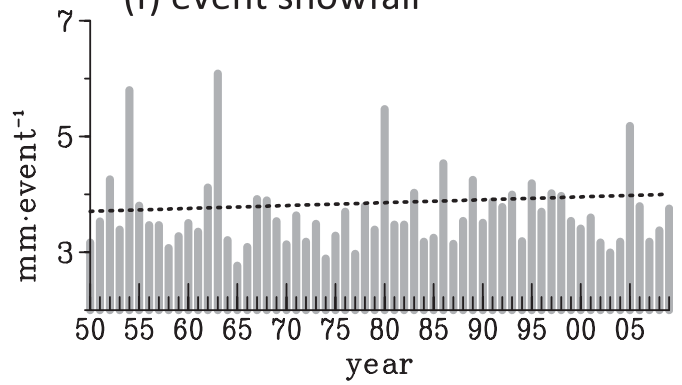

FIG. 12. (a) Precipitation, (b) rainfall, and (c) snowfall amounts per weather event (per day) over Utah from 1950 to 2009 for the trough-type pattern, overlaid with the linear trends (dotted line). (d)-(f) As in (a)-(c), but for the subtropical jet-type pattern. Data source is Maurer02+.

Canada, but the warming is noticeably weaker in the composite subtropical jet pattern and is absent over Utah (Fig. 13d). A weak warming such as this may explain the mild change in $S / P$ associated with the subtropical jet-type pattern. However, both types of weather patterns are associated with increased moisture over much of Utah and are accompanied by enhanced upward velocity over southern Utah; this feature lends support to the increased amount in event precipitation (cf. Fig. 12).
Moreover, the reduced upward velocity and weak increase in moisture north of Utah and in the Pacific Northwest is consistent with the declining precipitation that has been documented for this region (Regonda et al. 2005; Knowles et al. 2006). What is more, the reanalysis results here agree with those calculated from radiosonde observations, which similarly show increased temperature and increased specific humidity at $850 \mathrm{mb}$ over the central-western and northwestern United States (Dai 2006; 
Trough type

(a) $\Delta Z$ (contours), Trend in $T_{700 m b}$

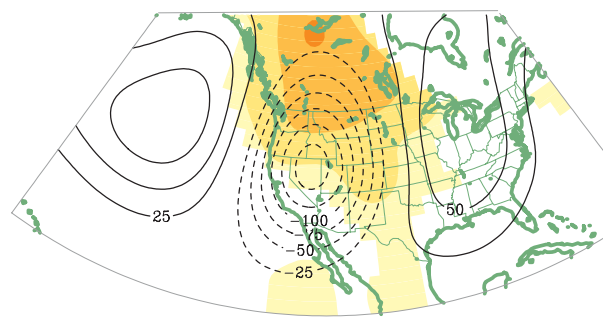

(b) $\Delta Z$ (contours), Trend in $\mathbf{q}_{700 \mathrm{mb}}$

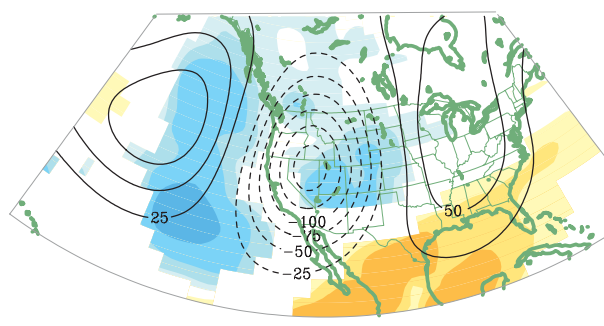

(c) $\Delta Z$ (contours), Trend in $\omega_{500 \mathrm{mb}}$

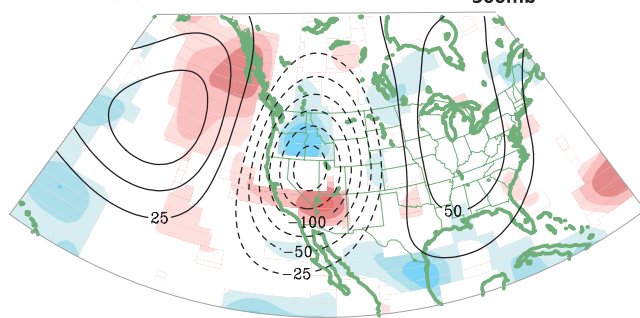

Subtropical-Jet type

(d) $\Delta Z$ (contours), Trend in $T_{700 \mathrm{mb}}$

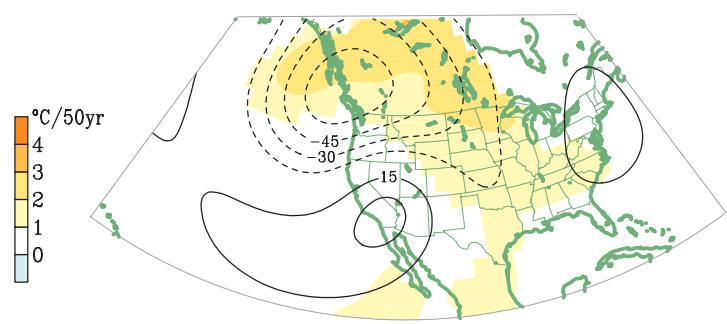

(e) $\Delta Z$ (contours), Trend in $\mathbf{q}_{700 m b}$

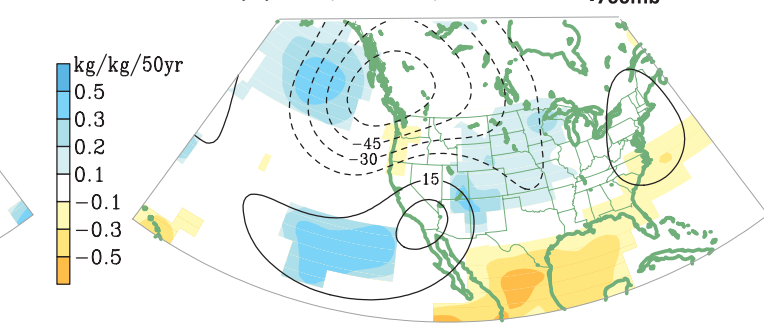

(f) $\Delta Z$ (contours), Trend in $\omega_{500 \mathrm{mb}}$

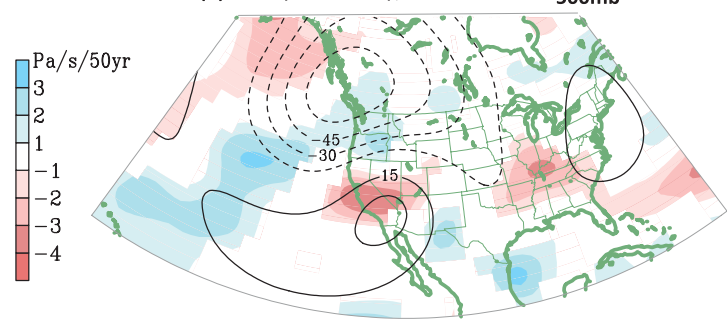

FIG. 13. Departures of composite 300-mb geopotential height from climatology (contours) overlaid with linear trends in the yearly composite of (a) 700-mb air temperature, (b) 700-mb specific humidity, and (c) 500-mb vertical velocity (upward is negative) for the trough-type weather pattern. (d)-(f) As in (a)-(c), but for the subtropical jet type.

McCarthy et al. 2009). The results are also in line with the theoretical increase in the local precipitation rate under a warming atmosphere caused by the increased moisture content that invigorates storms (through latent heat release; Trenberth 1998).

The implication of this concomitant analysis is that an average cyclone system (trough type) passing through Utah is producing more precipitation than before, with any increase occurring mostly in the form of rainfall rather than snowfall. Recently, Rasmussen et al. (2011) documented (using a high-resolution model) an increase of precipitation per synoptic event over Colorado, where similar increases in temperature and humidity have been observed. The precipitation time series in Fig. 12 also reveals a distinguishing attribute that is of note: the JFM precipitation and rainfall time series feature a marked quasi-decadal variability, corresponding to the fact that variations of the intermountain precipitation regimes are considerably modulated by the so-called Pacific quasidecadal oscillation (QDO) (Wang et al. 2010). These results also suggest that the Pacific QDO impacts Utah's seasonal climate by modulating the precipitation intensity associated with passing trough systems, possibly through enhanced (or suppressed) larger-scale moisture flows.

\section{3) LARGER-SCALE FEATURES}

The manual weather-tracking analysis was further supplemented by an objective analysis of the largescale circulations. We computed the linear trends of 300-mb geopotential height and 700-mb temperature fields over the Northern Hemisphere over the period 1950-2009 for the JFM season. As shown in Fig. 14a, an anomalous ridge has developed during the past $60 \mathrm{yr}$ in northwestern North America centered over the Canadian Rockies. Accompanying this ridge is distinct warming at $700 \mathrm{mb}$ (all the way to the tropopause; not shown). Since Utah is situated within this anomalous anticyclone and warming zone (Fig. 14a), there is a tendency for fewer cyclonic synoptic systems to be able to move into 


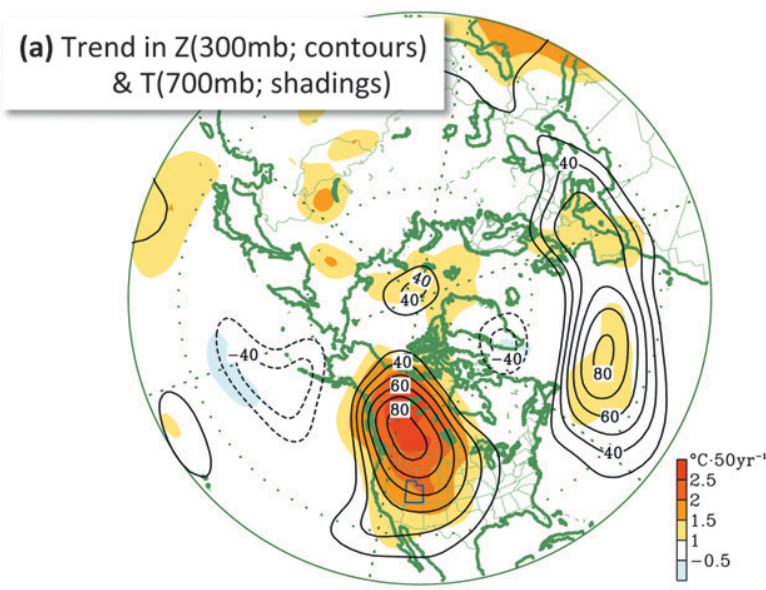

(b) Trend in Z(300mb; contours \& $\operatorname{RMS}\left[v^{\prime}(500 \mathrm{mb})\right.$; shadings $]$

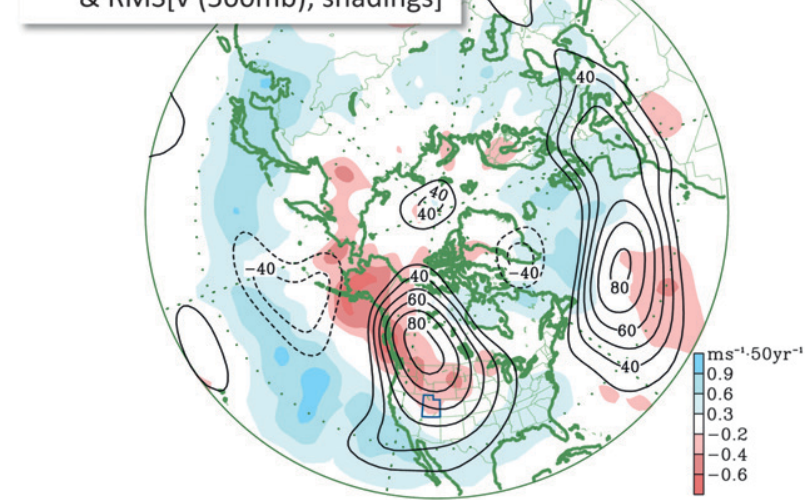

FIG. 14. Horizontal distribution of linear trends in 300-mb geopotential height (contours) overlaid with linear trends (shading) in (a) 700-mb air temperature and (b) the $500-\mathrm{mb}$ transient activity for January-March of 1950-2009.

the region from the west (shown later), while midtropospheric warming will tend to reduce the fraction of precipitation that falls as snow.

That fewer cyclonic synoptic systems are able to move into Utah is verified by the transient activity computed as the root-mean-square of the $500-\mathrm{mb}$ meridional winds band-pass filtered by $2-8$ days-denoted as $\operatorname{RMS}\left[v^{\prime}(500 \mathrm{mb})\right]$. The linear trend in $\operatorname{RMS}\left[v^{\prime}(500 \mathrm{mb})\right]$ (Fig. 14b) is a decreasing one over an elongated region from southern Alaska toward the Pacific Northwest, a region coincident with the common route taken by winter synoptic disturbances (e.g., Shafer and Steenburgh 2008); this is accompanied by increasing transient activity over southern California. Combined with the wavelike circulation anomalies, these synoptic conditions are reflective of a climate change pattern that signifies the poleward (equatorward) shift of storm tracks in the North Atlantic (North Pacific) as was depicted by Bengtsson et al. (2006). The decrease in transient activity across the Intermountain West, covering Utah, echoes the decline in the frequency of trough-type weather systems as was shown in Fig. 9c. There is also a possibility that the decline in trough-type weather events would itself contribute to lower tropospheric warming because of less cold air outbreaks. These circulation anomalies are further evidence that observed declines in snowpack and snow cover over Utah are not only attributed to warming at the surface (i.e., local forcing) but also related to a decrease in frequency of the snowfall weather pattern associated with the decreasing cyclone activity (i.e., remote forcing).

A further question that arises about such circulation change is to what extent is the declining frequency of the weather systems (particularly the trough type) involved in the declining $S / P$ and snowpack, compared to that which is attributed to lower-atmospheric warming? It is problematic to accurately account for such contributions as temperature changes in the lower troposphere are ambiguously linked to surface warming. Nevertheless, given the increase in rainfall and the weak change in snowfall totals in Utah, the only attributable factor to the documented decline in winter's end snowpack water content (such as 1 April) is temperature warming both at the surface and in the middle troposphere.

\section{Conclusions and discussion}

Previous studies have highlighted an increase in surface temperature that has been accompanied by a widespread decline in springtime snowpack, accompanied by a change in the precipitation regime observed in relative amounts falling as snow versus rain. Over Utah, these findings seem to contradict the overall increases in winter precipitation and mixed trends in snowfall water equivalent. Using a climatological approach to refine the RST method to delineate observation-based, gridded daily temperature and precipitation data over Utah, it was estimated that the proportion of winter (JanuaryMarch) precipitation falling as snow has decreased by $9 \%$ statewide over a half century, with greater reductions occurring at lower elevations $(<2000 \mathrm{~m})$. A decline in $S / P$ such as this has been accompanied by a marginal decrease in snow depth across the state, an observation supported by a consistent decrease in satelliteobserved snow cover and surface albedo. However, since 1950, the winter rainfall (and total precipitation) over Utah has increased without a significant change in snowfall.

A comprehensive synoptic analysis was undertaken. Through the tracking of weather systems that have the potential to produce precipitation in Utah, we noted 
that the trough-type patterns of both precipitation and snowfall have decreased in number with the snowfall pattern decreasing at twice the rate as that of the precipitation pattern. Combined with the increase in precipitation, the results point to an unambiguous increase in the event precipitation; this comprises mostly rainfall rather than snowfall. In other words, at least for Utah, there is a tendency toward stronger winter weather in terms of precipitation intensity; this tendency is particularly pronounced in the trough-type pattern (i.e., cyclone waves). We also found that the passing cyclones are associated with increased lower-tropospheric moisture accompanied by enhanced upward velocity, both of which are supportive of the increase in the event precipitation. Natural variability also plays a role, as the positive PDO phase (after 1977) appears to reduce further the $S / P$ associated with the trough-type weather pattern. Moreover, circulation analysis showed that the anomalous anticyclone that has developed over northwestern North America acts to reduce the synoptic transient activity along the cyclone track affecting the Intermountain West. When combined with an identified shift toward significant warming in the lower to middle troposphere, this anticyclone also reduces the likelihood of snowfall over the region.

The breadth of these analyses signifies that, while changes in the circulation and atmospheric conditions may explain the observed increase in winter precipitation, they do not lead to a long-term increase in snowfall. Therefore, early melting caused by surface and lower-tropospheric warming is mostly likely the reason for the decline in springtime snowpack, a feature that has been extensively documented. However, both the early melting and the decrease in $S / P$ are mild at high elevations relative to medium and low elevations; this feature may be worth noting in light of the record snowpack in 2011 spring. The elevation dependence of the change in snowpack, together with the coupling between a La Niña situation and an ongoing uptrend of the Pacific QDO (which increases precipitation in Utah; Gillies et al. 2011a), suggest that the abnormally high precipitation of the 2010/11 winter and the record snowpack over mountain peaks are within the realm of natural climate variability. On the other hand, given the ongoing retreat of snow line observed in Utah (Jones 2010), the effect of lower-tropospheric warming may add complexity to changes in high-elevation snowpack.

Acknowledgments. We are grateful to Dr. Andy Wood for providing the gridded data and helpful discussions. Valuable comments offered by Drs. Robert Davies, David Tarboton, Galina Guentchev, Aiguo Dai, and three anonymous reviewers are highly appreciated.
This study was supported by the USDA-CSREES funded Drought Management, Utah Project, and by the Utah Agricultural Experiment Station, Utah State University, as journal paper number 8256 .

\section{REFERENCES}

Alcott, T., and J. Steenburgh, 2010: Climatology and prediction of snow-to-liquid ratio at a high-mountain site. Wea. Forecasting, 25, 323-337.

Auer, A. H., 1974: The rain versus snow threshold temperatures. Weatherwise, 27, 67.

Barnett, T. P., J. C. Adam, and D. P. Lettenmaier, 2005: Potential impacts of a warming climate on water availability in snowdominated regions. Nature, 438, 303-309.

Baxter, M. A., C. E. Graves, and J. T. Moore, 2005: A climatology of snow-to-liquid ratio for the contiguous United States. Wea. Forecasting, 20, 729-744.

Bengtsson, L., K. I. Hodges, and E. Roeckner, 2006: Storm tracks and climate change. J. Climate, 19, 3518-3543.

Bliss, N. B., and L. M. Olsen, 1996: Development of a 30-arcsecond digital elevation model of South America. Proc. Pecora 13, Human Interactions with the Environment-Perspectives from Space, Sioux Falls, SD, ESRI, p. 382.

Cayan, D. R., S. A. Kammerdiener, M. D. Dettinger, J. M. Caprio, and D. H. Peterson, 2001: Changes in the onset of spring in the western United States. Bull. Amer. Meteor. Soc., 82, 399 415.

Chen, M., W. Shi, P. Xie, V. B. S. Silva, V. E. Kousky, R. Wayne Higgins, and J. E. Janowiak, 2008: Assessing objective techniques for gauge-based analyses of global daily precipitation. J. Geophys. Res., 113, D04110, doi:10.1029/2007JD009132.

Christensen, N. S., A. W. Wood, N. Voisin, D. P. Lettenmaier, and R. N. Palmer, 2004: Effects of climate change on the hydrology and water resources of the Colorado River Basin. Climatic Change, 62, 337-363.

Colle, B. A., and C. F. Mass, 1995: The structure and evolution of cold surges east of the Rocky Mountains. Mon. Wea. Rev., 123, 2577-2610.

,-- , and B. F. Smull, 1999: An observational and numerical study of a cold front interacting with the Olympic Mountains during COAST IOP5. Mon. Wea. Rev., 127, 1310-1334.

Dai, A., 2006: Recent climatology, variability, and trends in global surface humidity. J. Climate, 19, 3589-3606.

_ 2008: Temperature and pressure dependence of the rainsnow phase transition over land and ocean. Geophys. Res. Lett., 35, L12802, doi:10.1029/2008GL033295.

Dettinger, M. D., D. R. Cayan, M. K. Meyer, and A. E. Jeton, 2004: Simulated hydrologic responses to climate variations and change in the Merced, Carson, and American River basins, Sierra Nevada, California, 1900-2099. Climatic Change, 62, 283-317.

Gillies, R. R., O.-Y. Chung, S.-Y. Wang, and P. Kokoszka, 2011a: Incorporation of Pacific SSTs in a time series model towards a longer-term forecast for the Great Salt Lake elevation. J. Hydrometeor., 12, 474-480.

— , S.-Y. Wang, and W.-R. Huang, 2011b: Observational and supportive modeling analyses of winter precipitation change in China over the last half century. Int. J. Climatol., 32, 747758.

Guentchev, G., J. J. Barsugli, and J. Eischeid, 2010: Homogeneity of gridded precipitation datasets for the Colorado River basin. J. Appl. Meteor. Climatol., 49, 2404-2415. 
Hamlet, A. F., and D. P. Lettenmaier, 2005: Production of temporally consistent gridded precipitation and temperature fields for the continental United States. J. Hydrometeor., 6, 330-336.

_ P. W. Mote, M. P. Clark, and D. P. Lettenmaier, 2005: Effects of temperature and precipitation variability on snowpack trends in the western United States. J. Climate, 18, 45454561.

Hobbs, P. V., T. J. Matejka, P. H. Herzegh, J. D. Locatelli, and R. A. Houze Jr., 1980: The mesoscale and microscale structure and organization of clouds and precipitation in midlatitude cyclones. Part I: A case study of a cold front. J. Atmos. Sci., 37, $568-596$.

Howat, I. M., and S. Tulaczyk, 2005: Climate sensitivity of spring snowpack in the Sierra Nevada. J. Geophys. Res., 110, F04021, doi:10.1029/2005JF000356.

Jones, L. P., 2010: Assessing the sensitivity of Wasatch snowfall to temperature variations. M.S. thesis, University of Utah, Salt Lake City, UT, 66 pp.

Julander, R. P., 2010: Utah water supply outlook report. Proc. Utah Water Users Workshop. St. George, UT, Natural Resources Conservation Service, $8 \mathrm{pp}$. [Available online at http://www.ut.nrcs.usda.gov/snow/watersupply/wsor/2010/ wsor_sum_0210.pdf.]

_- and M. Bricco, cited 2006: An examination of external influences imbedded in the historical snow data of Utah. U.S. Government Documents (Utah Regional Depository) Paper 116. [Available online at http://digitalcommons.usu.edu/ govdocs/116.]

Kalnay, E., and Coauthors, 1996: The NCEP/NCAR 40-Year Reanalysis Project. Bull. Amer. Meteor. Soc., 77, 437-471.

Kanamitsu, M., W. Ebisuzaki, J. Woollen, S.-K. Yang, J. J. Hnilo, M. Fiorino, and G. L. Potter, 2002: NCEP/DOE AMIP-II Reanalysis (R-2). Bull. Amer. Meteor. Soc., 83, $1631-1643$.

Karl, T. R., C. N. Williams Jr., F. T. Quinlan, and T. A. Boden, 1990: United States Historical Climatology Network (HCN) serial temperature and precipitation data. Carbon Dioxide Information and Analysis Center, Oak Ridge National Laboratory, Environmental Science Division Publication 3404, 389 pp.

_ , and Coauthors, 1993: A new perspective on recent global warming: Asymmetric trends of daily maximum and minimum temperature. Bull. Amer. Meteor. Soc., 74, 1007-1023.

Knowles, N., M. D. Dettinger, and D. R. Cayan, 2006: Trends in snowfall versus rainfall in the western United States. J. Climate, 19, 4545-4559.

Legates, D. R., and C. J. Willmott, 1990: Mean seasonal and spatial variability in gauge-corrected, global precipitation. Int. J. Climatol., 10, 111-127.

Lettenmaier, D. P., and T. Y. Gan, 1990: Hydrologic sensitivities of the Sacramento-San Joaquin River Basin, California, to global warming. Water Resour. Res., 26, 69-86.

Leung, L. R., and S. J. Ghan, 1999: Pacific Northwest climate sensitivity simulated by a regional climate model driven by a GCM. Part I: Control simulations. J. Climate, 12, 20102030.

_ Y. Qian, X. Bian, W. M. Washington, J. Han, and J. O. Roads, 2004: Mid-century ensemble regional climate change scenarios for the western United States. Climatic Change, 62 , 75-113.

Lundquist, J. D., P. J. Neiman, B. Martner, A. B. White, D. J. Gottas, and F. M. Ralph, 2008: Rain versus snow in the Sierra
Nevada, California: Comparing Doppler profiling radar and surface observations of melting Level. J. Hydrometeor., 9, 194-211.

Mantua, N. J., S. R. Hare, Y. Zhang, J. M. Wallace, and R. C. Francis, 1997: A Pacific interdecadal climate oscillation with impacts on salmon production. Bull. Amer. Meteor. Soc., 78, 1069-1079.

Maurer, E. P., A. W. Wood, J. C. Adam, D. P. Lettenmaier, and B. Nijssen, 2002: A long-term hydrologically-based dataset of land surface fluxes and states for the conterminous United States. J. Climate, 15, 3237-3251.

McCabe, G. J., and D. M. Wolock, 1999: General circulation model simulations of future snowpack in the western United States. J. Amer. Water Resour. Assoc., 35, 1473-1484.

McCarthy, M. P., P. W. Thorne, and H. A. Titchner, 2009: An analysis of tropospheric humidity trends from radiosondes. J. Climate, 22, 5820-5838.

Moller, A. L., and R. R. Gillies, 2008: Utah Climate. 2nd ed. Utah State University, $109 \mathrm{pp}$.

Mote, P. W., 2006: Climate-driven variability and trends in mountain snowpack in western North America. J. Climate, 19, 62096220.

Pierce, D. W., and Coauthors, 2008: Attribution of declining western U.S. snowpack to human effects. J. Climate, 21, 64256444.

Pupacko, A., 1993: Variations in northern Sierra Nevada streamflow: Implications of climate change. Water Resour. Bull., 29, 283-290.

Qian, Y., W. I. Gustafson Jr., L. R. Leung, and S. J. Ghan, 2009: Effects of soot-induced snow albedo change on snowpack and hydrological cycle in western United States based on Weather Research and Forecasting chemistry and regional climate simulations. J. Geophys. Res., 114, D03108, doi:10.1029/ 2008JD011039.

Rasmussen, R., and Coauthors, 2011: High-resolution coupled climate runoff simulations of seasonal snowfall over Colorado: A process study of current and warmer climate. J. Climate, 24, 3015-3048.

Regonda, S., M. P. Clark, B. Rajagopalan, and J. Pitlick, 2005: Seasonal cycle shifts in hydroclimatology over the western United States. J. Climate, 18, 372-384.

Shafer, J. C., and W. J. Steenburgh, 2008: Climatology of strong Intermountain cold fronts. Mon. Wea. Rev., 136, 784-807.

Stewart, I. T., D. R. Cayan, and M. D. Dettinger, 2004: Changes in snowmelt runoff timing in western North America under a 'business as usual' climate change scenario. Climatic Change, 62, 217-232.

,-- , and $\_,$2005: Changes toward earlier streamflow timing across western North America. J. Climate, 18, 11361155 .

Strong, C., and G. Magnusdottir, 2009: The role of tropospheric Rossby wave breaking in the Pacific decadal oscillation. J. Climate, 22, 1819-1833.

Trenberth, K. E., 1998: Atmospheric moisture residence times and cycling: Implications for rainfall rates with climate change. Climatic Change, 39, 667-694.

Uppala, S. M., and Coauthors, 2005: The ERA-40 Re-Analysis. Quart. J. Roy. Meteor. Soc., 131, 2961-3012, doi:10.1256/ qj.04.176.

, D. Dee, S. Kobayashi, P. Berrisford, and A. Simmons, 2008: Towards a climate data assimilation system: Status update of ERA-Interim. ECMWF Newsletter, No. 115, ECMWF, Reading, United Kingdom, 12-18. 
U.S. Army Corps of Engineers, 1956: Snow hydrology: Summary report of the snow investigations. U.S. Army Corps of Engineers, North Pacific Division Rep., 435 pp.

Wang, S.-Y., R. R. Gillies, J. Jin, and L. E. Hipps, 2009a: Recent rainfall cycle in the intermountain region as a quadrature amplitude modulation from the Pacific decadal oscillation. Geophys. Res. Lett., 36, L02705, doi:10.1029/2008GL036329.

, E. S. Takle, and W. J. Gutowski Jr., 2009b: Evaluation of precipitation in the intermountain region as simulated by the NARCCAP regional climate models. Geophys. Res. Lett., 36, L11704, doi:10.1029/2009GL037930.

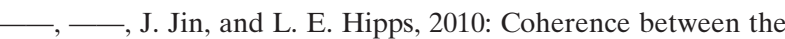
Great Salt Lake level and the Pacific quasi-decadal oscillation. J. Climate, 23, 2161-2177.

Yang, Z.-L., R. E. Dickinson, A. Robock, and K. Y. Vinnikov, 1997: Validation of the snow submodel of the biosphereatmosphere transfer scheme with Russian snow cover and meteorological observational data. J. Climate, 10, 353-373.

Yuter, S. E., D. E. Kingsmill, L. B. Nance, and M. Löffler-Mang, 2006: Observations of precipitation size and fall speed characteristics within coexisting rain and wet snow. J. Appl. Meteor. Climatol., 45, 1450-1464. 